\title{
Ground-based remote sensing of tropospheric water vapour isotopologues within the project MUSICA
}

\author{
M. Schneider ${ }^{1,2}$, S. Barthlott ${ }^{1}$, F. Hase ${ }^{1}$, Y. González ${ }^{2}$, K. Yoshimura ${ }^{3}$, O. E. García ${ }^{2}$, E. Sepúlveda ${ }^{4,2}$, \\ A. Gomez-Pelaez ${ }^{2}$, M. Gisi ${ }^{1}$, R. Kohlhepp ${ }^{1}$, S. Dohe ${ }^{1}$, T. Blumenstock ${ }^{1}$, A. Wiegele ${ }^{1}$, E. Christner ${ }^{1}$, K. Strong ${ }^{5}$, \\ D. Weaver ${ }^{5}$, M. Palm ${ }^{6}$, N. M. Deutscher ${ }^{6,8}$, T. Warneke ${ }^{6}$, J. Notholt ${ }^{6}$, B. Lejeune ${ }^{7}$, P. Demoulin ${ }^{7}$, N. Jones ${ }^{8}$, \\ D. W. T. Griffith ${ }^{8}$, D. Smale ${ }^{9}$, and J. Robinson ${ }^{9}$ \\ ${ }^{1}$ Institute for Meteorology and Climate Research (IMK-ASF), Karlsruhe Institute of Technology (KIT), Germany \\ ${ }^{2}$ Izaña Atmospheric Research Centre (IARC), Agencia Estatal de Meteorología (AEMET), Spain \\ ${ }^{3}$ University of Tokyo, Tokyo, Japan \\ ${ }^{4}$ Laguna University, Tenerife, Spain \\ ${ }^{5}$ Department of Physics, University of Toronto, Toronto, Ontario, Canada \\ ${ }^{6}$ Institute of Environmental Physics, University of Bremen, Bremen, Germany \\ ${ }^{7}$ Institute of Astrophysics and Geophysics, University of Liège, Liège, Belgium \\ ${ }^{8}$ Centre for Atmospheric Chemistry, University of Wollongong, Wollongong, New South Wales, Australia \\ ${ }^{9}$ National Institute of Water and Atmospheric Research, Lauder, New Zealand
}

Correspondence to: M. Schneider (matthias.schneider@kit.edu)

Received: 20 July 2012 - Published in Atmos. Meas. Tech. Discuss.: 2 August 2012

Revised: 12 November 2012 - Accepted: 14 November 2012 - Published: 5 December 2012

\begin{abstract}
Within the project MUSICA (MUlti-platform remote Sensing of Isotopologues for investigating the Cycle of Atmospheric water), long-term tropospheric water vapour isotopologue data records are provided for ten globally distributed ground-based mid-infrared remote sensing stations of the NDACC (Network for the Detection of Atmospheric Composition Change). We present a new method allowing for an extensive and straightforward characterisation of the complex nature of such isotopologue remote sensing datasets. We demonstrate that the MUSICA humidity profiles are representative for most of the troposphere with a vertical resolution ranging from about $2 \mathrm{~km}$ (in the lower troposphere) to $8 \mathrm{~km}$ (in the upper troposphere) and with an estimated precision of better than $10 \%$. We find that the sensitivity with respect to the isotopologue composition is limited to the lower and middle troposphere, whereby we estimate a precision of about $30 \%$ or for the ratio between the two isotopologues $\mathrm{HD}^{16} \mathrm{O}$ and $\mathrm{H}_{2}^{16} \mathrm{O}$. The measurement noise, the applied atmospheric temperature profiles, the uncertainty in the spectral baseline, and the cross-dependence on humidity are the leading error sources. We introduce an a posteriori correction method of the cross-dependence on humidity, and
\end{abstract}

we recommend applying it to isotopologue ratio remote sensing datasets in general. In addition, we present mid-infrared $\mathrm{CO}_{2}$ retrievals and use them for demonstrating the MUSICA network-wide data consistency.

In order to indicate the potential of long-term isotopologue remote sensing data if provided with a well-documented quality, we present a climatology and compare it to simulations of an isotope incorporated AGCM (Atmospheric General Circulation Model). We identify differences in the multiyear mean and seasonal cycles that significantly exceed the estimated errors, thereby indicating deficits in the modeled atmospheric water cycle.

\section{Introduction}

The water cycle is comprised of the continuous evaporation, transport, and condensation of water. This cycle strongly interacts with the global energy and radiation budgets (latent heat exchange and the radiation effects of water vapour and clouds) and is closely linked to the development of different climate zones. Despite its fundamental importance for 
climate on global as well as regional scales, important details of this cycle are still not completely understood. One example is the latent heat budget, whose importance for the global atmospheric energy budget remains unclear (Worden et al., 2007; Trenberth et al., 2009). Another example is the greenhouse effect of water vapour and its future evolution, which deserves further attention since most climate models show a significant wet bias in the upper troposphere, where the radiative effect of water vapour is particularly strong (Pierrehumbert, 1995; Spencer and Braswell, 1997).

In this context, measurements of atmospheric water isotopologues (e.g. $\mathrm{H}_{2}{ }^{16} \mathrm{O}$ and $\mathrm{HD}^{16} \mathrm{O}$ ) are very promising. In the following, we express $\mathrm{H}_{2}{ }^{16} \mathrm{O}$ and $\mathrm{HD}^{16} \mathrm{O}$ as $\mathrm{H}_{2} \mathrm{O}$ and $\mathrm{HDO}$, respectively, and $\frac{\mathrm{HD}^{16} \mathrm{O}}{\mathrm{H}_{2}{ }^{16} \mathrm{O}}$ in the $\delta$-notation

$\delta \mathrm{D}=1000 \% \circ \times\left(\frac{\mathrm{HD}^{16} \mathrm{O} / \mathrm{H}_{2}{ }^{16} \mathrm{O}}{\mathrm{SMOW}}-1\right)$,

where SMOW $=3.1152 \times 10^{-4}$ (standard mean ocean water; Craig, 1961). Combined observations of atmospheric $\mathrm{H}_{2} \mathrm{O}$ and $\delta \mathrm{D}$ yield insights in troposphere-stratosphere exchange (Kuang et al., 2003), cloud processes (Webster and Heymsfield, 2003; Schmidt et al., 2005), rain recycling and evapotranspiration (Worden et al., 2007), and the processes that control upper tropospheric humidity (Risi et al., 2012a). Water vapour isotopic measurements can be used to efficiently discriminate between the representation of the processes controlling the atmospheric humidity distribution in different models (Risi et al., 2012b).

However, the water isotopologue measurements are very demanding. This is particularly true for remote sensing observations of tropospheric water vapour isotopologue ratios, which have recently become available (Schneider et al., 2006b; Worden et al., 2006; Frankenberg et al., 2009; Schneider and Hase, 2011; Lacour et al., 2012; Boesch et al., 2012; Frankenberg et al., 2012). The remote sensing techniques are very important since they can provide continuous data on a quasi-global scale; however, for their correct interpretation, one has to be well aware of the complex nature of these observational data.

In this regard and in order to assure a proper usage of the remote sensing data, our paper characterises in detail the tropospheric water vapour isotopologue data produced by the ground-based remote sensing component of the European Research Council project MUSICA (MUlti-platform remote Sensing of Isotopologues for investigating the Cycle of Atmospheric water, www.imk-asf.kit.edu/english/musica). We propose a data treatment that assures a high data quality and allows for a straightforward and extensive characterisation of such remote sensing datasets, thereby facilitating their correct interpretation. Although our paper deals exclusively with the ground-based MUSICA remote sensing dataset, the proposed data treatment can be applied to all water vapour isotopologue remote sensing datasets. Therefore, we think that the paper can serve as a guideline for the different re- search teams producing water vapour isotopologue remote sensing data.

The outline of the paper is as follows: In Sect. 2 we give a very brief overview of the history of tropospheric water isotopologue observations and present the new strategy applied within the project MUSICA. In Sect. 3, the ground-based remote sensing component of MUSICA is described and the particularities of isotopologue remote sensing retrievals in general are explained. In Sect. 4, we extensively document the sensitivity and the uncertainty of the ground-based MUSICA remote sensing data and propose a method for significantly reducing the cross-dependence between humidity and the isotopologue ratio, which is a retrieval artefact. Section 5 documents the network-wide consistency of the ground-based MUSICA data. In Sect. 6, we present the first MUSICA water vapour isotopologue climatology and compare it to simulations of an isotopic AGCM (Atmospheric General Circulation Model). Section 7 briefly summarizes our work.

\section{Atmospheric water isotopologue observations}

\subsection{Brief review}

Tropospheric water vapour concentrations are very variable (e.g. at sea level in mid-latitudes, $\mathrm{H}_{2} \mathrm{O}$ vapour concentrations can range between less than $2500 \mathrm{ppm}$ on a cold dry day and more than $50000 \mathrm{ppm}$ on a warm humid day). Compared to this large variability, the ratios of the water isotopologues, like $\delta \mathrm{D}$, are relatively invariable, which makes their measurement a difficult task; it requires techniques that are, firstly, sensitive over the large dynamic range of atmospheric water vapour concentrations, and secondly and at the same time, very precise in order to capture the small isotopic signals. In the past, such stringent precision requirements were only achieved by in-situ mass spectrometry techniques. The systematic observation of tropospheric water isotopologues started in 1961 in the framework of the GNIP (Global Network of Isotopes in Precipitation, http: //www-naweb.iaea.org/napc/ih/IHS_resources_gnip.html). A decade later, (Ehhalt, 1974) made the first aircraft-based observations of tropospheric water vapour isotopologue profiles. Due to the complex and time-consuming operation and calibration of these in-situ instruments, the measurements have been limited to a few campaigns only (e.g. Zahn, 2001; Webster and Heymsfield, 2003).

Recently, new in-situ as well as remote sensing instrumentation and sophisticated retrieval algorithms have been developed. For instance, it has been shown that continuous insitu observations of atmospheric water vapour isotopologues at the Earth's surface are now possible (e.g. Tremoy et al., 2011; Aemisegger et al., 2012). The developments in the field of remote sensing now allow for monitoring of the water vapour isotopologues throughout the troposphere. Schneider 
et al. (2006b, 2010b) present a method for the remote sensing of tropospheric $\mathrm{H}_{2} \mathrm{O}$ and $\delta \mathrm{D}$ from the ground using FTIR (Fourier transform infrared) spectrometer systems of the NDACC (Network for the Detection of Atmospheric Composition Change, http://www.acd.ucar.edu/irwg/). If performed from space, remote sensing observations can provide data on a quasi-global scale. The sensors MIPAS, SMR, and ACE allow for $\delta \mathrm{D}$ observations within and above the upper troposphere/lower stratosphere region (Steinwagner et al., 2007; Payne et al., 2007; Nassar et al., 2007; Lossow et al., 2011). Worden et al. (2006) and Frankenberg et al. (2009) perform the first space-based remote sensing observations of tropospheric $\delta \mathrm{D}$ using the US and European research satellite sensors TES and SCIAMACHY, respectively. More recently, Frankenberg et al. (2012) and Boesch et al. (2012) report tropospheric $\delta \mathrm{D}$ observations using the Japanese research satellite sensor GOSAT. Herbin et al. (2009) document that different tropospheric water vapour isotopologues can be well detected by the operational meteorological satellite sensor: IASI (Infrared Atmospheric Sounding Interferometer) flown aboard the METOP satellite of EUMETSAT (European Organisation for the Exploitation of Meteorological Satellites). First IASI $\mathrm{H}_{2} \mathrm{O}$ and $\delta$ D retrievals are presented by Schneider and Hase (2011) and Lacour et al. (2012).

\subsection{The new strategy of MUSICA}

These recent developments are very promising, but further efforts are needed for generating a tropospheric $\mathrm{H}_{2} \mathrm{O}$ and $\delta \mathrm{D}$ dataset with a well-documented quality. In this context, the project MUSICA has been established. It will provide quasiglobal and homogenous tropospheric $\mathrm{H}_{2} \mathrm{O}$ and $\delta \mathrm{D}$ data to the scientific community, and it will extensively document its quality. To reach this goal, MUSICA combines in-situ with ground- and space-based remote sensing observations:

- The ground-based remote sensing component: It consists of several ground-based FTIR experiments operated within NDACC at globally distributed sites. This component covers different geophysical locations (Arctic, mid-latitudes and subtropics of the Northern and Southern Hemispheres, and Antarctic) and provides tropospheric $\mathrm{H}_{2} \mathrm{O}$ and $\delta \mathrm{D}$ profiles dating back at some stations to the mid 1990s.

- The space-based remote sensing component: It uses the IASI sensor aboard the operational meteorological satellite METOP. IASI combines high temporal, horizontal, and spectral resolution (covers the whole globe twice per day, measures nadir pixels with a diameter of only $12 \mathrm{~km}$ ), and records thermal radiation between 645 and $2760 \mathrm{~cm}^{-1}$ at a resolution of $0.5 \mathrm{~cm}^{-1}$. Its operation started in 2007 and is guaranteed on a series of three METOP satellites until 2020. The good degree of consistency between MUSICA's ground- and space-based

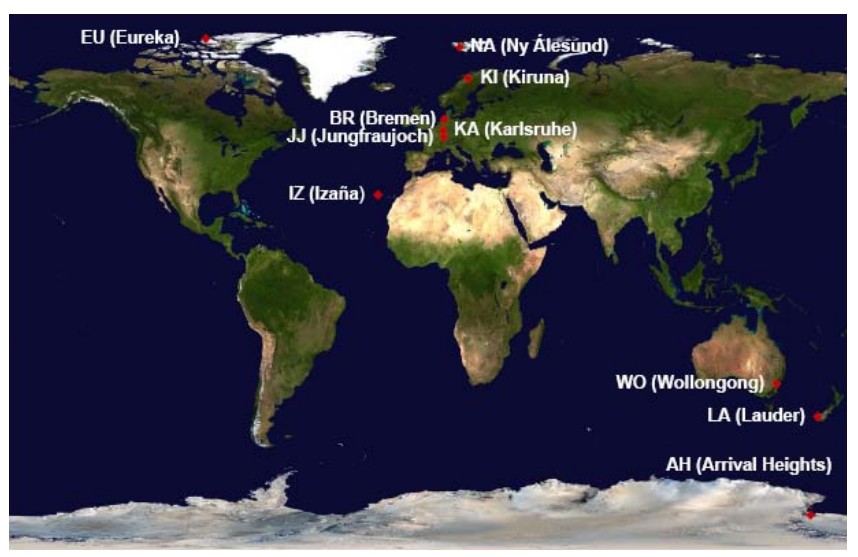

Fig. 1. Global distribution of the ground-based NDACC-FTIR stations contributing to MUSICA.

components has already been documented by Schneider and Hase (2011).

- The in-situ measurement component: It consists of continuous ground-based measurements using two Picarro L2120-i water isotopologue analyzers (Aemisegger et al., 2012), a first one at Karlsruhe (110 m a.s.l., representative of the boundary layer) and a second one at Izaña ( $2370 \mathrm{~m}$ a.s.l., representative of the free troposphere). Both instruments have been in operation since the beginning of 2012. Moreover, two aircraft campaigns measuring tropospheric water isotopologue profiles above Izaña applying the ISOWAT instrument (Dyroff et al., 2010) are planned for the near future. These in-situ measurements will allow validation of the remote sensing dataset.

This paper focuses on MUSICA's ground-based remote sensing component.

\section{MUSICA's ground-based remote sensing component}

\subsection{The network}

Figure 1 shows a global map with the ten ground-based NDACC-FTIR stations that contribute to MUSICA. The instruments are run by different MUSICA collaborators, which provide the recorded spectra to the MUSICA retrieval team (for more details about the collaborators see Table 1). Subsequently the MUSICA retrieval team analyses all the spectra in a uniform way, thereby ensuring a good consistency of the ground-based remote sensing water isotopologue data.

\subsection{The measurement and retrieval principle}

The ground-based FTIR systems measure solar absorption spectra using a high-resolution Fourier transform spectrometer. The high-resolution spectra allow the observation of the 
Table 1. List of the ten initial ground-based FTIR MUSICA stations.

\begin{tabular}{|c|c|c|c|c|}
\hline Site (acronym) & $\begin{array}{l}\text { Location and } \\
\text { altitude }\end{array}$ & $\begin{array}{l}\text { Instrumentation } \\
\text { (Bruker IFS) }\end{array}$ & Reference & Collaborator \\
\hline Eureka (EU) & $\begin{array}{l}80.1^{\circ} \mathrm{N}, 86.4^{\circ} \mathrm{W} \\
610 \mathrm{~m} \text { a.s.1. }\end{array}$ & $125 \mathrm{HR}$ & Batchelor et al. (2009) & University of Toronto \\
\hline Ny Ålesund (NA) & $\begin{array}{l}78.9^{\circ} \mathrm{N}, 11.9^{\circ} \mathrm{W} \\
15 \mathrm{~m} \text { a.s.l. }\end{array}$ & $120 \mathrm{HR}$ & Notholt et al. (1995) & $\begin{array}{l}\text { University of Bremen, } \\
\text { Alfred Wegener Institute }\end{array}$ \\
\hline Kiruna (KI) & $\begin{array}{l}67.8^{\circ} \mathrm{N}, 20.4^{\circ} \mathrm{E} \\
419 \mathrm{~m} \text { a.s.l. }\end{array}$ & $120 / 5 \mathrm{HR}$ & Blumenstock et al. (2006) & $\begin{array}{l}\text { Karlsruhe Inst. of Tech., } \\
\text { Inst. for Space Phys. Kiruna }\end{array}$ \\
\hline Bremen (BR) & $\begin{array}{l}53.1^{\circ} \mathrm{N}, 8.9^{\circ} \mathrm{E} \\
27 \mathrm{~m} \text { a.s.l. }\end{array}$ & $125 \mathrm{HR}$ & Velazco et al. (2007) & University of Bremen \\
\hline Karlsruhe (KA) & $\begin{array}{l}49.1^{\circ} \mathrm{N}, 8.4^{\circ} \mathrm{E} \\
111 \mathrm{~m} \text { a.s.l. }\end{array}$ & $125 \mathrm{HR}$ & Gisi et al. (2011) & Karlsruhe Inst. of Tech. \\
\hline Jungfraujoch (JJ) & $\begin{array}{l}46.6^{\circ} \mathrm{N}, 8.0^{\circ} \mathrm{E} \\
3580 \mathrm{~m} \text { a.s. } 1 .\end{array}$ & $120 \mathrm{HR}$ & Zander et al. (2008) & University of Liège \\
\hline Izaña (IZ) & $\begin{array}{l}28.3^{\circ} \mathrm{N}, 16.5^{\circ} \mathrm{E} \\
2367 \mathrm{~m} \text { a.s.l. }\end{array}$ & $\begin{array}{l}120 \mathrm{M} \\
125 \mathrm{HR} \text { (since 2005) }\end{array}$ & Schneider et al. (2005) & $\begin{array}{l}\text { Karlsruhe Inst. of Tech., } \\
\text { Agencia Estatal de Met. }\end{array}$ \\
\hline Wollongong (WO) & $\begin{array}{l}34.4^{\circ} \mathrm{S}, 150.9^{\circ} \mathrm{E} \\
30 \mathrm{~m} \text { a.s.1. }\end{array}$ & $125 \mathrm{HR}$ & Kohlhepp et al. (2012) & University of Wollongong \\
\hline Lauder (LA) & $\begin{array}{l}45.1^{\circ} \mathrm{S}, 169.7^{\circ} \mathrm{E} \\
370 \mathrm{~m} \text { a.s.l. }\end{array}$ & $\begin{array}{l}120 \mathrm{M} \\
120 \mathrm{HR} \text { (since 2001) }\end{array}$ & Kohlhepp et al. (2012) & $\begin{array}{l}\text { National Institute of Water } \\
\text { and Atmospheric Research }\end{array}$ \\
\hline Arrival Heights (AH) & $\begin{array}{l}77.8^{\circ} \mathrm{S}, 166.7^{\circ} \mathrm{E} \\
250 \mathrm{~m} \text { a.s. } 1 .\end{array}$ & $120 \mathrm{M}$ & Kohlhepp et al. (2012) & $\begin{array}{l}\text { National Institute of Water } \\
\text { and Atmospheric Research }\end{array}$ \\
\hline
\end{tabular}

pressure broadening effect, and thus the retrieval of trace gas profiles. However, the inversion problem is ill determined, and for its solution some kind of regularisation is required. It can be introduced by means of a cost function:

$$
\begin{gathered}
{[\boldsymbol{y}-\boldsymbol{F}(\boldsymbol{x}, \boldsymbol{p})]^{T} \mathbf{S}_{\epsilon}^{-1}[\boldsymbol{y}-\boldsymbol{F}(\boldsymbol{x}, \boldsymbol{p})]} \\
+\left[\boldsymbol{x}-\boldsymbol{x}_{\mathrm{a}}\right]^{T} \mathbf{S}_{\mathrm{a}}{ }^{-1}\left[\boldsymbol{x}-\boldsymbol{x}_{\mathrm{a}}\right] .
\end{gathered}
$$

Here, the first term is a measure of the difference between the measured spectrum $(\boldsymbol{y})$ and the spectrum simulated for a given atmospheric state $(\boldsymbol{x})$, where $\boldsymbol{F}$ represents the forward model, which simulates a spectra $\boldsymbol{y}$ for a given state $\boldsymbol{x}$, taking into account the actual measurement noise level $\left(\mathbf{S}_{\epsilon}\right.$ is the measurement noise covariance). The vector $\boldsymbol{p}$ represents auxiliary atmospheric parameters (like temperature) or instrumental characteristics (like the instrumental line shape). The second term of the cost function (2) is the regularisation term. It constrains the atmospheric solution state $(\boldsymbol{x})$ towards an a priori state $\left(\boldsymbol{x}_{\mathrm{a}}\right)$, whereby the kind and the strength of the constraint are defined by the matrix $\mathbf{S}_{\mathrm{a}}$. The constrained solution is reached at the minimum of the cost function (2).

Since the equations involved in atmospheric radiative transfer are non-linear, the cost function (2) is minimised iteratively by a Gauss-Newton method. The solution for the $(i+1)$ th iteration is

$$
\begin{gathered}
\boldsymbol{x}_{\boldsymbol{i}+\mathbf{1}}=\boldsymbol{x}_{\mathrm{a}}+\mathbf{S}_{\mathrm{a}} \mathbf{K}_{\mathbf{i}}^{T}\left(\mathbf{K}_{\mathbf{i}} \mathbf{S}_{\mathrm{a}} \mathbf{K}_{\mathbf{i}}^{T}+\mathbf{S}_{\epsilon}\right)^{-1} \\
{\left[\boldsymbol{y}-\boldsymbol{F}\left(\boldsymbol{x}_{\boldsymbol{i}}\right)+\mathbf{K}_{\mathbf{i}}\left(\boldsymbol{x}_{\boldsymbol{i}}-\boldsymbol{x}_{\mathrm{a}}\right)\right],}
\end{gathered}
$$

whereby $\mathbf{K}$ is the Jacobian matrix which samples the derivatives $\partial y / \partial x$ (changes in the spectral fluxes $\boldsymbol{y}$ for changes in the vertical distribution of the absorber $\boldsymbol{x}$ ).
An important addendum of the retrieved solution vector is the averaging kernel matrix A. It samples the derivatives $\partial \hat{x} / \partial x$ (changes in the retrieved concentration $\hat{x}$ for changes in the actual atmospheric concentration $x$ ) describing the smoothing of the real atmospheric state by the remote sensing measurement process:

$\left(\hat{\boldsymbol{x}}-\boldsymbol{x}_{\mathrm{a}}\right)=\mathbf{A}\left(\boldsymbol{x}-\boldsymbol{x}_{\mathrm{a}}\right)$.

Providing these kernels is rather important since they document what is actually measured by the remote sensing system. Without this information, the remote sensing data cannot be used in a sensible manner. In addition, the trace of $\mathbf{A}$ quantifies the amount of information introduced by the measurement. It can be interpreted in terms of degrees of freedom of signal (DOFS) of the measurement.

These retrieval methods are standard in the field of atmospheric remote sensing (e.g. Rodgers, 2000). We address the inversion problem by the retrieval code PROFFIT (Hase et al., 2004), which has been used for many years by the ground-based FTIR community for evaluating highresolution solar absorption spectra. PROFFIT supports retrieval options that are essential for the remote sensing of isotopologue ratios. It allows for retrievals on a logarithmic scale (the atmospheric state vector, the a priori state, the a priori covariance matrix, and the Jacobians have to be transferred to a logarithmic scale). This option has proven to be very beneficial for tropospheric water vapour retrievals. The reason is that tropospheric water vapour concentrations are log-normally, rather than normally, distributed, and therefore 
the regularisation term of the cost function (2) only works adequately on a log scale (Schneider et al., 2006a).

The log-scale retrieval is also required for constraining ratios of absorbing species. Since $\ln \frac{[\mathrm{HDO}]}{\left[\mathrm{H}_{2} \mathrm{O}\right]}=\ln [\mathrm{HDO}]-$ $\ln \left[\mathrm{H}_{2} \mathrm{O}\right]$, we can easily introduce an $\mathrm{HDO} / \mathrm{H}_{2} \mathrm{O}$ constraint in the regularisation term of the cost function (2): we only have to fill in the respective elements of the matrix $\mathbf{S}_{\mathrm{a}}$ (Schneider et al., 2006b). The $\mathrm{HDO} / \mathrm{H}_{2} \mathrm{O}$ ratio constraint is essential for obtaining an appropriate tropospheric $\mathrm{HDO} / \mathrm{H}_{2} \mathrm{O}$ estimate. The reason is that the $\mathrm{H}_{2} \mathrm{O}$ and HDO kernels are rather different and tropospheric $\mathrm{H}_{2} \mathrm{O}$ and HDO distributions are very inhomogeneous.

PROFFIT is currently the only retrieval code for groundbased FTIR remote sensing that supports an operational calculation of error Jacobian matrices. This feature allows assignment of error bars to each individual measurement.

Furthermore, the radiative transfer model implemented in PROFFIT (called PROFFWD) supports different spectroscopic line shape models, which is particularly important when retrieving water vapour profiles from very highresolution spectra (Schneider et al., 2011).

\subsection{The tropospheric water vapour state}

The main characteristics of tropospheric water vapour are its large variability and the strong correlation between the different isotopologues (e.g. $\mathrm{H}_{2} \mathrm{O}$ and $\mathrm{HDO}$ ). In comparison to this large correlated variability, the ratio of the isotopologues remains significantly more invariable, and the a priori covariance of the $\left\{\ln \left[\mathrm{H}_{2} \mathrm{O}\right], \ln [\mathrm{HDO}]\right\}$-state can be defined by the following matrix $\mathbf{S}_{\mathrm{a}}$ :

$\mathbf{S}_{\mathrm{a}}=\left(\begin{array}{ll}\mathbf{S}_{\mathrm{aH}}+\frac{1}{4} \mathbf{S}_{\mathrm{aI}} & \mathbf{S}_{\mathrm{aH}}-\frac{1}{4} \mathbf{S}_{\mathrm{aI}} \\ \mathbf{S}_{\mathrm{aH}}-\frac{1}{4} \mathbf{S}_{\mathrm{aI}} & \mathbf{S}_{\mathrm{aH}}+\frac{1}{4} \mathbf{S}_{\mathrm{aI}}\end{array}\right)$,

where $\mathbf{S}_{\mathrm{aH}}$ and $\mathbf{S}_{\mathrm{aI}}$ are symmetric $n \times n$ matrices ( $n$ is the number of atmospheric levels used by the forward model). The entries of $\mathbf{S}_{\mathrm{aI}}$ are rather small if compared to the entries of $\mathbf{S}_{\mathrm{aH}}$, which accounts for the strong a priori connection between $\ln \left[\mathrm{H}_{2} \mathrm{O}\right]$ and $\ln [\mathrm{HDO}]$.

Equation (5) describes the a priori covariance in the $\left\{\ln \left[\mathrm{H}_{2} \mathrm{O}\right], \ln [\mathrm{HDO}]\right\}$-basis. However, since the two isotopologues do not vary independently, there might be a better orthogonal basis for describing the tropospheric water vapour state. The rows of $\mathbf{P}$ describe this basis: the first $n$ rows span the $\left\{\left(\ln \left[\mathrm{H}_{2} \mathrm{O}\right]+\ln [\mathrm{HDO}]\right) / 2\right\}$-state, and the second $n$ rows the $\left\{\ln [\mathrm{HDO}]-\ln \left[\mathrm{H}_{2} \mathrm{O}\right]\right\}$-state:

$$
\mathbf{P}=\left(\begin{array}{cc}
\frac{1}{2} \mathbb{I} & \frac{1}{2} \mathbb{I} \\
-\mathbb{I} & \mathbb{I}
\end{array}\right) .
$$

Here, II stands for an $n \times n$ identity matrix. In the new orthogonal basis, the a priori covariance is

$$
\begin{aligned}
\mathbf{S}_{\mathrm{a}}^{\prime}= & \mathbf{P S}_{\mathrm{a}} \mathbf{P}^{T} \\
= & \left(\begin{array}{cc}
\frac{1}{2} \mathbb{I} & \frac{1}{2} \mathbb{I} \\
-\mathbb{I} & \mathbb{I}
\end{array}\right)\left(\begin{array}{cc}
\mathbf{S}_{\mathrm{aH}}+\frac{1}{4} \mathbf{S}_{\mathrm{aI}} & \mathbf{S}_{\mathrm{aH}}-\frac{1}{4} \mathbf{S}_{\mathrm{aI}} \\
\mathbf{S}_{\mathrm{aH}}-\frac{1}{4} \mathbf{S}_{\mathrm{aI}} & \mathbf{S}_{\mathrm{aH}}+\frac{1}{4} \mathbf{S}_{\mathrm{aI}}
\end{array}\right) \\
& \left(\begin{array}{cc}
\frac{1}{2} \mathbb{I} & -\mathbb{I} \\
\frac{1}{2} \mathbb{I} & \mathbb{I}
\end{array}\right)=\left(\begin{array}{cc}
\mathbf{S}_{\mathrm{aH}} & 0 \\
0 & \mathbf{S}_{\mathrm{aI}}
\end{array}\right) .
\end{aligned}
$$

The transformation reveals that the vectors $\left(\ln \left[\mathrm{H}_{2} \mathrm{O}\right]+\ln [\mathrm{HDO}]\right) / 2$ and $\ln [\mathrm{HDO}]-\ln \left[\mathrm{H}_{2} \mathrm{O}\right]$ span the adequate basis for describing the tropospheric water vapour state and that $\mathbf{S}_{\mathrm{aH}}$ and $\mathbf{S}_{\mathrm{aI}}$ are the a priori covariance matrices for $\left(\ln \left[\mathrm{H}_{2} \mathrm{O}\right]+\ln [\mathrm{HDO}]\right) / 2$ and $\ln [\mathrm{HDO}]-\ln \left[\mathrm{H}_{2} \mathrm{O}\right]$, respectively.

The introduction of an $\ln [\mathrm{HDO}]-\ln \left[\mathrm{H}_{2} \mathrm{O}\right]$ constraint by using an $\mathbf{S}_{\mathrm{a}}$ as described by Eq. (5) is fundamental for most isotopologue ratio remote sensing retrievals (Worden et al., 2006; Schneider et al., 2006b, 2011; Lacour et al., 2012). According to Eq. (7), such retrievals constrain $\left(\ln \left[\mathrm{H}_{2} \mathrm{O}\right]+\right.$ $\ln [\mathrm{HDO}]) / 2$ and $\ln [\mathrm{HDO}]-\ln \left[\mathrm{H}_{2} \mathrm{O}\right]$ independently. In this context, the following two relations, relating these independently constrained states to $\mathrm{H}_{2} \mathrm{O}$ and $\delta \mathrm{D}$, are important:

$$
\begin{aligned}
& \Delta\left(\frac{\ln \left[\mathrm{H}_{2} \mathrm{O}\right]+\ln [\mathrm{HDO}]}{2}\right) \approx \frac{\Delta\left(\sqrt{\left[\mathrm{H}_{2} \mathrm{O}\right][\mathrm{HDO}]}\right)}{\sqrt{\left[\mathrm{H}_{2} \mathrm{O}\right][\mathrm{HDO}]}} \\
& \quad \approx \frac{\Delta\left[\mathrm{H}_{2} \mathrm{O}\right]}{\left[\mathrm{H}_{2} \mathrm{O}\right]}
\end{aligned}
$$

and

$$
\begin{gathered}
\Delta\left(\ln [\mathrm{HDO}]-\ln \left[\mathrm{H}_{2} \mathrm{O}\right]\right) \approx \frac{\Delta\left(\frac{[\mathrm{HDO}]}{\left[\mathrm{H}_{2} \mathrm{O}\right]}\right)}{\frac{[\mathrm{HDO}]}{\left[\mathrm{H}_{2} \mathrm{O}\right]}} \\
\gtrsim \frac{\Delta\left(\frac{[\mathrm{HDO}]}{\left[\mathrm{H}_{2} \mathrm{O}\right]}\right)}{\mathrm{SMOW}}=\Delta(\delta \mathrm{D}) .
\end{gathered}
$$

According to Eq. (8), the variations in $\left(\ln \left[\mathrm{H}_{2} \mathrm{O}\right]+\right.$ $\ln [\mathrm{HDO}]) / 2$ are well representative of relative variations of the geometric mean between $\mathrm{H}_{2} \mathrm{O}$ and HDO. Since $\mathrm{H}_{2} \mathrm{O}$ and HDO vary almost in parallel, the relative variations of their geometric mean represent very well the relative variations of $\mathrm{H}_{2} \mathrm{O}$ (and $\mathrm{HDO}$ ), and consequently we can document the sensitivity, vertical resolution, and errors of $\mathrm{H}_{2} \mathrm{O}$ (and HDO) by examining the sensitivity, vertical resolution, and errors of the $\left\{\left(\ln \left[\mathrm{H}_{2} \mathrm{O}\right]+\ln [\mathrm{HDO}]\right) / 2\right\}$-state. Furthermore, Eq. (8) reveals that the covariance matrix $\mathbf{S}_{\mathrm{aH}}$ well represents the covariances of $\mathrm{H}_{2} \mathrm{O}$ (or HDO). In the following, we use relative variations of the geometric mean between $\mathrm{H}_{2} \mathrm{O}$ and $\mathrm{HDO}$ as a synonym for relative variation of atmospheric humidity.

According to Eq. (9), the variations in $\ln [\mathrm{HDO}]-\ln \left[\mathrm{H}_{2} \mathrm{O}\right]$ can be used as a proxy for $\delta \mathrm{D}$ variations. We can use $\ln [\mathrm{HDO}]-\ln \left[\mathrm{H}_{2} \mathrm{O}\right]$ for documenting the sensitivity and vertical resolution of $\delta \mathrm{D}$. The errors of the $\{\ln [\mathrm{HDO}]-$ $\left.\ln \left[\mathrm{H}_{2} \mathrm{O}\right]\right\}$-state are good conservative proxies of $\delta \mathrm{D}$ errors. Moreover, Eq. (9) means that the covariance matrix $\mathbf{S}_{\mathrm{aI}}$ well represents the covariances of $\delta \mathrm{D}$. 


\subsection{The retrieval setup}

Figure 2 shows the spectral microwindows that are used for the ground-based MUSICA water vapour isotopologue analysis. The microwindows have strong, but mostly not saturated, and well-isolated $\mathrm{H}_{2}{ }^{16} \mathrm{O}$ and $\mathrm{HD}^{16} \mathrm{O}$ absorption lines. In addition, there are spectroscopic features of $\mathrm{O}_{3}, \mathrm{~N}_{2} \mathrm{O}$, $\mathrm{CH}_{4}, \mathrm{HCl}$, and $\mathrm{C}_{2} \mathrm{H}_{6}$ which are all fitted simultaneously. For the line-by-line simulations of these spectral signatures, we apply the HITRAN 2008 spectroscopic line parameters (Rothman et al., 2009), whereby for the water vapour isotopologues we use parameters that have been adjusted for the speed-dependent Voigt line shape (Schneider et al., 2011).

The targeted water isotopologues are retrieved on a log scale and regularised in an optimal estimation manner applying the a priori covariance matrix $\mathbf{S}_{\mathrm{a}}$ of Eq. (5). The matrix $\mathbf{S}_{\mathrm{aH}}$, which represents the a priori covariances of $\mathrm{H}_{2} \mathrm{O}$ (or $\mathrm{HDO}$ ), as well as the applied $\mathrm{H}_{2} \mathrm{O}$ a priori profile are deduced from the tropospheric water vapour covariances observed by radiosonde measurements at different locations. In the stratosphere we use an $\mathrm{H}_{2} \mathrm{O}$ climatology provided for the analysis of MIPAS observations (J. J. Remedios, University of Leicester, personal communication, 2007). The matrix $\mathbf{S}_{\mathrm{aI}}$, which represents the a priori covariances of $\delta \mathrm{D}$, as well as the applied $\delta \mathrm{D}$ a priori profile are deduced from the climatology as measured by (Ehhalt, 1974).

The applied humidity log-scale a priori profiles decrease linearly between the lower and upper troposphere, whereby we use three different altitude levels for defining the upper limit of the troposphere: $7.5 \mathrm{~km}$ for the polar sites, $10 \mathrm{~km}$ for the mid-latitude sites, and $12.5 \mathrm{~km}$ for the subtropical sites. For calculating $\mathbf{S}_{\mathrm{aH}}$ we use a tropospheric $1 \sigma$ variability of 1.0 (on log scale) and gradually decrease it to 0.25 above the upper troposphere. As correlation length we assume $2.5 \mathrm{~km}$ within the troposphere and at higher altitudes we increase it gradually to $10 \mathrm{~km}$. The isotopologue ratio a priori profiles decrease between the lower and upper troposphere (sitedependent between $-100 \%$ and $-700 \%$ ), and slowly increase within the stratosphere. For calculating $\mathbf{S}_{\mathrm{aI}}$ we assume a tropospheric $\delta \mathrm{D}$ variability of $80 \%$ and the same vertical correlation length as for $\mathbf{S}_{\mathrm{aH}}$.

Simultaneously to the water vapour microwindows of Fig. 2, we fit four $\mathrm{CO}_{2}$ lines of different strength, which allows us to optimally estimate the temperature from the measured spectra (Schneider and Hase, 2008). As a priori temperature profile, we use the analysis data from the National Centers for Environmental Prediction (NCEP). As temperature uncertainty covariance, we assume an uncertainty correlation length of $10 \mathrm{~km}$ (excluding the boundary layer) and uncertainty values of $2 \mathrm{~K}$ in the boundary layer, $1 \mathrm{~K}$ throughout the rest of the troposphere, and $5 \mathrm{~K}$ above the tropopause.

Moreover, we determine the spectral shift between the solar and telluric lines during a pre-fit of a spectral microwindow at $2703.2-2705.3 \mathrm{~cm}^{-1}$ containing well-isolated solar as well as telluric lines of $\mathrm{CH}_{4}$.

\section{Characterisation of water vapour isotopologue remote sensing data}

Already, Schneider et al. (2006b), Worden et al. (2006), and Schneider and Hase (2011) have presented approaches for characterising the complex nature of the isotopologue remote sensing data. Schneider et al. (2006b) estimated errors by varying the retrieval parameters according to their uncertainty levels. This method works well for an exemplary dataset, but it is not practicable for estimating individual errors for a large number of observations. Worden et al. (2006) derive formulae, which allow for an analytic error estimation. These formulae work in the $\left\{\ln \left[\mathrm{H}_{2} \mathrm{O}\right], \ln [\mathrm{HDO}]\right\}$-state and address the complex nature of the $\delta \mathrm{D}$ product by $\mathrm{H}_{2} \mathrm{O}$ and HDO cross terms. These cross terms add significant complexity compared to the remote sensing error estimation formulae described in the textbook of C. D. Rodgers (Rodgers, 2000). Furthermore, in the $\left\{\ln \left[\mathrm{H}_{2} \mathrm{O}\right], \ln [\mathrm{HDO}]\right\}$-state it is difficult to comprehensively document the FTIR system's $\delta \mathrm{D}$ sensitivity and the cross-dependence of retrieved $\delta \mathrm{D}$ on real atmospheric humidity.

In this section, we present a new method that transfers the $\left\{\ln \left[\mathrm{H}_{2} \mathrm{O}\right], \ln [\mathrm{HDO}]\right\}$-state onto a $\{$ Humidity, $\delta \mathrm{D}\}$-proxy state. This approach allows for a $\delta \mathrm{D}$ error estimation in analogy to Rodgers (2000) as well as a straightforward documentation of the vertical resolution, sensitivity, and the crossdependence of retrieved $\delta \mathrm{D}$ on atmospheric humidity. Furthermore, we develop an a posteriori data treatment that significantly increases the scientific value of the isotopologue remote sensing data.

We apply this new method for extensively characterising the water vapour isotopologue dataset produced by the ground-based remote sensing component of the project MUSICA. This dataset offers two types of products: first, tropospheric $\mathrm{H}_{2} \mathrm{O}$ profiles aiming at maximal vertical resolution and best possible sensitivity from the lower up to the upper troposphere, and second, tropospheric profiles of the isotopic composition of water vapour aiming at the best possible degree of consistency between the $\mathrm{H}_{2} \mathrm{O}$ and $\delta \mathrm{D}$ profiles and a maximal quality of the $\delta \mathrm{D}$ data.

We do the characterisation in detail for the two product types taking the Izaña station as an example and subsequently present an overall picture for all ten stations of the ground-based MUSICA network.

\subsection{Characterisation of product type 1 : optimally estimated $\mathrm{H}_{2} \mathrm{O}$ profiles}

Figure 3 depicts averaging kernel matrices of the water vapour state (for the first product type, which aims on maximal vertical resolution and best possible sensitivity for humidity). Panel (a) shows the row kernels in the $\left\{\ln \left[\mathrm{H}_{2} \mathrm{O}\right], \ln [\mathrm{HDO}]\right\}$-basis (kernel matrix $(\mathbf{A})$ ). The row kernels reveal the atmospheric altitude regions that are represented by the retrieved state. The kernel matrix (A) can be 


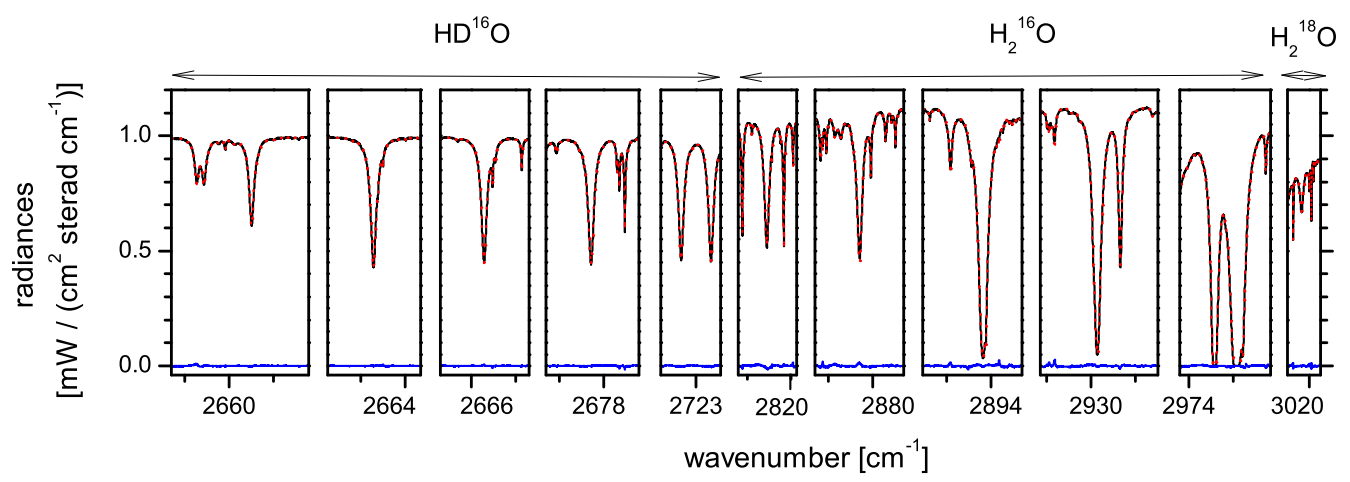

Fig. 2. Spectral microwindows used for the ground-based FTIR MUSICA retrievals. Shown is an example for a typical measurement at Izaña (26 October 2011, 11:02 UT; solar elevation: 41.7 ${ }^{\circ} \mathrm{H}_{2} \mathrm{O}$ slant column: $6.3 \mathrm{~mm}$; DOFS for $\mathrm{H}_{2} \mathrm{O}$ : 2.95). Black line: measurement; red dashed line: simulation; blue line: residual (difference between measurement and simulation).
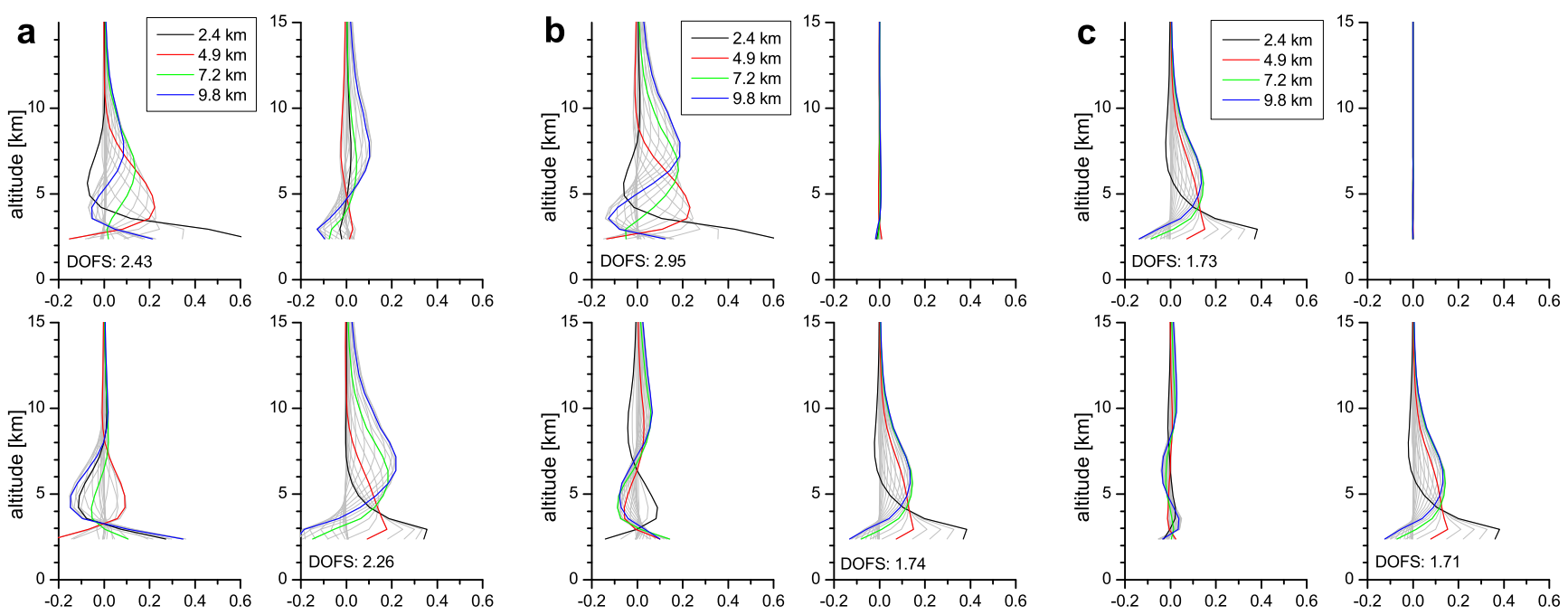

Fig. 3. Row kernels of the water vapour state corresponding to the example spectrum of Fig. 2. (a) $\operatorname{In} \operatorname{the}\left\{\ln \left[\mathrm{H}_{2} \mathrm{O}\right]\right.$, $\left.\ln [\mathrm{HDO}]\right\}$-basis; (b) in the $\left\{\left(\ln \left[\mathrm{H}_{2} \mathrm{O}\right]+\ln \left[\mathrm{H}_{2} \mathrm{O}\right]\right) / 2, \ln [\mathrm{HDO}]-\ln \left[\mathrm{H}_{2} \mathrm{O}\right]\right\}$-basis; (c) same as (b), but optimized for isotopologue studies (see text for more details).

split up in four quadrants: the upper left graph documents the altitude regions of real atmospheric $\ln \left[\mathrm{H}_{2} \mathrm{O}\right]$ variations that affect retrieved $\ln \left[\mathrm{H}_{2} \mathrm{O}\right]$, the upper right graph the altitudes of real atmospheric $\ln [\mathrm{HDO}]$ variations that affect retrieved $\ln \left[\mathrm{H}_{2} \mathrm{O}\right]$, the lower left graph the altitudes of real atmospheric $\ln \left[\mathrm{H}_{2} \mathrm{O}\right]$ that affect retrieved $\ln [\mathrm{HDO}]$, and the lower right graph the altitude regions of real atmospheric $\ln [\mathrm{HDO}]$ that affect retrieved $\ln [\mathrm{HDO}]$, respectively. It can be observed that the retrieved $\ln \left[\mathrm{H}_{2} \mathrm{O}\right]$ amount is affected by both variations in $\ln \left[\mathrm{H}_{2} \mathrm{O}\right]$ and $\ln [\mathrm{HDO}]$. The same is true for the retrieved $\ln [\mathrm{HDO}]$ amounts.

Since $\mathrm{H}_{2} \mathrm{O}$ and $\mathrm{HDO}$ vary largely in parallel, the $\ln \left[\mathrm{H}_{2} \mathrm{O}\right]$ and $\ln [\mathrm{HDO}]$ kernels can be calculated by co-adding the dependence on real atmospheric $\ln \left[\mathrm{H}_{2} \mathrm{O}\right]$ and $\ln [\mathrm{HDO}]$ variations. Alternatively and according to Eq. (8), we can use the kernel of the $\left\{\left(\ln \left[\mathrm{H}_{2} \mathrm{O}\right]+\ln [\mathrm{HDO}]\right) / 2\right\}$-state as a proxy for the kernels of both $\mathrm{H}_{2} \mathrm{O}$ and HDO. This kernel can be visualised by a transformation of $\mathbf{A}$ onto the basis described by the rows of matrix $\mathbf{P}$ :

$$
\begin{aligned}
\mathbf{A}^{\prime} & =\mathbf{P} \mathbf{A} \mathbf{P}^{-1} \\
& =\left(\begin{array}{cc}
\mathbf{A}_{\mathrm{HH}}^{\prime} & \mathbf{A}_{\mathrm{IH}}^{\prime} \\
\mathbf{A}_{\mathrm{HI}}^{\prime} & \mathbf{A}_{\mathrm{II}}^{\prime}
\end{array}\right) .
\end{aligned}
$$

The part of $\mathbf{A}^{\prime}$ corresponding to the $\left\{\left(\ln \left[\mathrm{H}_{2} \mathrm{O}\right]+\right.\right.$ $\ln [\mathrm{HDO}]) / 2\}$-state is depicted in the upper left graph of panel (b). We call this kernel $\mathbf{A}_{\mathrm{HH}}^{\prime}$, whereby the indices " $\mathrm{H}$ " stand for humidity (as aforementioned, we use relative variations of humidity as synonym for relative variations of the geometric mean between $\mathrm{H}_{2} \mathrm{O}$ and $\mathrm{HDO}$ ).

\subsubsection{Sensitivity and vertical resolution}

The kernel $\mathbf{A}_{\mathrm{HH}}^{\prime}$ indicates that the ground-based FTIR technique allows for distinguishing three tropospheric $\mathrm{H}_{2} \mathrm{O}$ layers (see also the previous works of, for example, Schneider et al., 2006a, 2010a; Schneider and Hase, 2009): a first layer 

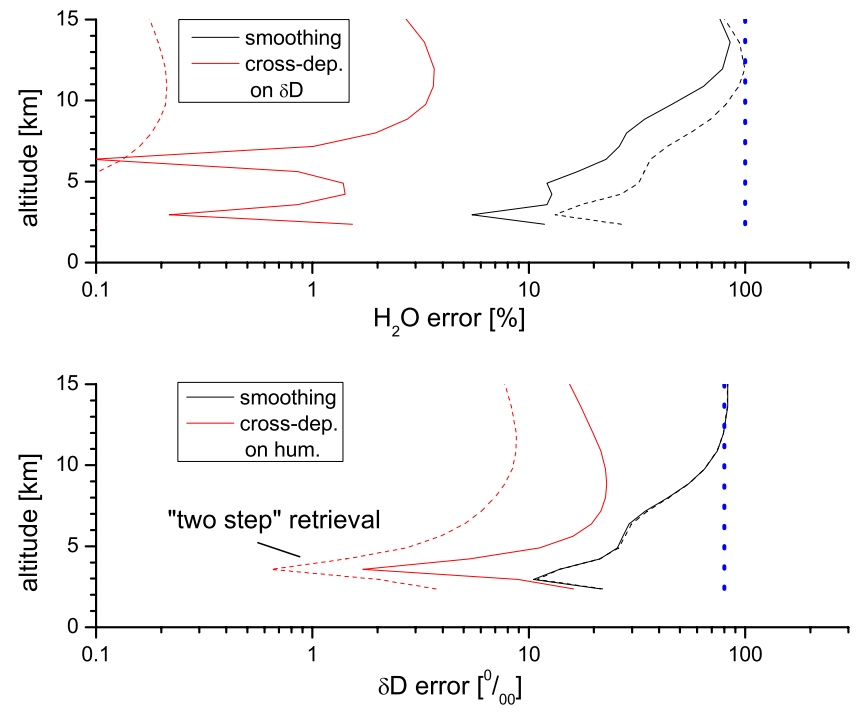

Fig. 4. Smoothing error and error due to cross-dependence (black and red lines, respectively) for Izaña. Top panel: $\mathrm{H}_{2} \mathrm{O}$; bottom panel: $\delta \mathrm{D}$; solid lines: before applying the a posteriori operator $\mathbf{C}$ of Eq. (14); and dashed lines: after applying the operator $\mathbf{C}$. The blue dashed line indicates the natural variability.

representing the lower troposphere (full width at half maximum, FWHM, of about $2-3 \mathrm{~km}$ ), a second one representing the middle troposphere (FWHM of $5 \mathrm{~km}$ ), and a third one representing the upper troposphere (FWHM of $8 \mathrm{~km}$ ).

The $\mathrm{H}_{2} \mathrm{O}$ smoothing error covariance matrix $\left(\mathbf{S}_{\mathrm{sH}}^{\prime}\right)$ can be calculated by

$\mathbf{S}_{\mathrm{sH}}^{\prime}=\left(\mathbf{A}_{\mathrm{HH}}^{\prime}-\mathbb{I}\right) \mathbf{S}_{\mathrm{aH}}\left(\mathbf{A}_{\mathrm{HH}}^{\prime}-\mathbb{I}\right)^{T}$.

The square root values of the diagonal elements of $\mathbf{S}_{\mathrm{sH}}^{\prime}$ are depicted as a black solid line in the upper panel of Fig. 4 together with the a priori uncertainty, i.e. the natural variability, of tropospheric $\mathrm{H}_{2} \mathrm{O}$ (thick blue dashed line). As can be seen, the FTIR measurements significantly reduce the a priori uncertainty up to an altitude of about $12 \mathrm{~km}$. The smoothing error of the total $\mathrm{H}_{2} \mathrm{O}$ column is about $0.1 \%$ (see Table 3). Please note that the errors at different altitudes are often anticorrelated, which explains the relatively small total column error if compared to the errors in the profile (the correlation between the different altitudes is not visible in the square root values of the error covariance matrix as depicted in Fig. 4).

The kernel $\mathbf{A}_{\mathrm{IH}}^{\prime}$ (upper right plot of panel (b) of Fig. 3, whereby the index "I" stands for isotopologue ratio) documents that real atmospheric variation in the isotopologue ratio very slightly affects the retrieved humidity. Please be aware that we scaled this kernel by a factor of 0.08 . In this scale the kernels $\mathbf{A}_{\mathrm{IH}}^{\prime}$ and $\mathbf{A}_{\mathrm{HH}}^{\prime}$ are comparable, since it accounts for the different magnitudes of the humidity and isotopologue ratio variations. The slight cross-dependence of retrieved humidity on atmospheric $\delta \mathrm{D}$ variations gives rise to a very small error, whose error covariance can be calculated by (similar to Sussmann and Borsdorff, 2007)

$\mathbf{S}_{\mathrm{cH}}^{\prime}=\mathbf{A}_{\mathrm{IH}}^{\prime} \mathbf{S}_{\mathrm{aI}} \mathbf{A}_{\mathrm{IH}}^{\prime T}$.

The square root values of the diagonal elements of $\mathbf{S}_{\mathrm{cH}}^{\prime}$ are depicted in the upper panel of Fig. 4 as a red solid line. It is very small $(<3 \%$ throughout the troposphere), and its effect on the total column error can be neglected.

\subsubsection{Estimation of uncertainties}

Table 2 collects the uncertainties that we use for our theoretical error estimation. We use a measurement noise of $0.4 \%$ (defined as noise to signal ratio), which corresponds to the value typically observed for white noise in the measured spectra. By analysing saturated absorption lines, we conclude that baseline uncertainties should be generally smaller than about $0.2 \%$. Furthermore, we consider an instrumental line shape uncertainty of $10 \%$ concerning the modulation efficiency, and of $0.1 \mathrm{rad}$ concerning the phase error. These are conservative values for the ILS variations that we observe when analysing low pressure gas cell measurements over several years and for different instruments by means of the software LINEFIT (Hase et al., 1999). For the a priori used temperature profile, we assume an uncertainty of about $3 \mathrm{~K}$. The uncertainty values for the line of sight and the solar line signatures are chosen to be in agreement with the observed variations in the spectral shift of the solar with respect to the telluric lines (due to the Doppler effect and the rotation of the Sun, a non-central pointing of the solar disc causes a shift of the solar line). For the spectroscopic intensity and broadening parameters of $\mathrm{H}_{2} \mathrm{O}$ and $\mathrm{HDO}$, we use uncertainty values of $1 \%-2 \%$, which correspond to the values as estimated by (Schneider et al., 2011).

The errors are calculated as the square root of the diagonal of the error covariance matrix $\mathbf{S}_{\mathrm{e}}^{\prime}$ :

$\mathbf{S}_{\mathrm{e}}^{\prime}=\mathbf{P G K}_{p} \mathbf{S}_{p} \mathbf{K}_{p}^{T} \mathbf{G}^{T} \mathbf{P}^{T}$,

where $\mathbf{G}=\left(\mathbf{K}^{T} \mathbf{S}_{\epsilon}^{-1} \mathbf{K}+\mathbf{S}_{\mathrm{a}}^{-1}\right)^{-1} \mathbf{K}^{T} \mathbf{S}_{\epsilon}^{-1}$ is the gain matrix, which samples the derivatives $\partial \hat{x} / \partial y$ (changes in the retrieved $\left\{\ln \left[\mathrm{H}_{2} \mathrm{O}\right], \ln [\mathrm{HDO}]\right\}$-state $\hat{x}$ for changes at the spectral bin $y$ ); $\mathbf{K}_{p}$ is the parameter Jacobian, which samples the derivatives $\partial y / \partial p$ (changes at the spectral bin $y$ for changes in the parameter $p$ ); and $\mathbf{S}_{p}$ is the uncertainty covariance matrix for parameter $p$. Equation (13) is the analytic error estimation as suggested by Rodgers (2000), but with the error covariance in the $\left\{\left(\ln \left[\mathrm{H}_{2} \mathrm{O}\right]+\ln [\mathrm{HDO}]\right) / 2\right.$, $\left.\ln [\mathrm{HDO}]-\ln \left[\mathrm{H}_{2} \mathrm{O}\right]\right\}$-basis $(\mathbf{P}$ is the basis transformation matrix of Eq. 6). According to Eq. (8), the error of the $\left\{\left(\ln \left[\mathrm{H}_{2} \mathrm{O}\right]+\ln [\mathrm{HDO}]\right) / 2\right\}$-state is a good proxy for the $\mathrm{H}_{2} \mathrm{O}$ error.

Figure 5 depicts the resulting $\mathrm{H}_{2} \mathrm{O}$ profile error estimates (panel (a) for the statistical and panel (b) for the systematic uncertainty assumptions, respectively). We observe that baseline and atmospheric temperature uncertainties are the 
Table 2. Experimental and temperature uncertainty sources used for our error estimation. The third column gives the uncertainty value and the fourth column the partitioning between statistical and systematic sources.

\begin{tabular}{llll}
\hline Error source & Acronym & Uncertainty & $\begin{array}{c}\text { Statistical/ } \\
\text { systematic }\end{array}$ \\
\hline Measurement noise & NOI & $0.4 \%$ & $100 / 0$ \\
Baseline (channeling and offset) & BAS & $0.2 \%$ and $0.1 \%$ & $50 / 50$ \\
Mod. eff. and pha. err. & ILS & $10 \%$ and $0.1 \mathrm{rad}$ & $50 / 50$ \\
Temperature profile & TEM & $1-5 \mathrm{~K}$ & $70 / 30$ \\
Line of sight & LOS & $0.1^{\circ}$ & $90 / 10$ \\
Solar lines (Intensity and $\nu$-scale) & SOL & $1 \%$ and $10^{-6}$ & $80 / 20$ \\
Spectroscopic parameters $(S$ and $\gamma)$ & SPE & $1 \%\left(\mathrm{H}_{2}{ }^{16} \mathrm{O}\right) ; 2 \%\left(\mathrm{HD}^{16} \mathrm{O}\right)$ & $0 / 100$ \\
\hline
\end{tabular}

Table 3. Statistical and systematic errors in the Izaña total $\mathrm{H}_{2} \mathrm{O}$ column due to the assumed experimental and temperature uncertainty sources of Table 2. The "Total (TOT)" data represent the rootsquare-sums of these errors. In addition, the error due to the limited vertical sensitivity and resolution of the remote sensing system is given (smoothing error).

\begin{tabular}{lrr}
\hline Error (acronym) & Statistical & Systematic \\
\hline NOI & $0.6 \%$ & - \\
BAS & $0.4 \%$ & $0.4 \%$ \\
ILS & $<0.1 \%$ & $<0.1 \%$ \\
TEM & $0.2 \%$ & $0.1 \%$ \\
LOS & $0.2 \%$ & $<0.1 \%$ \\
SOL & $<0.1 \%$ & $<0.1 \%$ \\
SPE & - & $1.0 \%$ \\
Total (TOT) & $0.8 \%$ & $1.1 \%$ \\
Smoothing error & $0.1 \%$ & - \\
\hline
\end{tabular}

leading random error sources. The total random error is about $5 \%$ throughout the troposphere. The systematic errors are clearly dominated by spectroscopic parameter uncertainties and can reach up to $10 \%$. An uncertainty of the instrumental line shape (ILS), which is a leading error source for the ground-based remote sensing of stratospheric trace gas profiles (e.g. Schneider et al., 2008; García et al., 2012), is of lower importance for tropospheric water vapour retrievals. The reason is that most water vapour is situated at low altitudes. Consequently, the absorption signatures are rather broad (pressure broadening effect) and a precise knowledge of the modulation efficiency is less important.

Table 3 collects the estimations for the total column errors of $\mathrm{H}_{2} \mathrm{O}$. Measurement noise and baseline uncertainties are the leading random error sources. We estimate that the precision of the total column $\mathrm{H}_{2} \mathrm{O}$ data is better than $1 \%$. This very high precision has already been documented in previous studies (e.g. Schneider et al., 2006a; Sussmann et al., 2009). Please recall that errors at different altitudes are often anticorrelated, so total column error cannot be assessed from the square root of the diagonal values of the error covariance matrix plotted in Fig. 5. The systematic error of the total $\mathrm{H}_{2} \mathrm{O}$ column is determined by uncertainties in the spectroscopic line parameters.

\subsection{Characterisation of product type 2: consistent $\mathrm{H}_{2} \mathrm{O}$ and $\delta \mathrm{D}$ data}

When combined with humidity measurements, the isotopologue ratio measurements provide complementary information on the history of the observed water mass. However, it is important that the remote sensing products of humidity and isotopologue ratio are representative of the same atmospheric air mass. Furthermore, since the variability in the ratio of the isotopologues is very small if compared to the large variability of humidity, we need to be careful with a possible crossdependence of the retrieved isotopologue ratios on humidity.

The lower right graph of panel (b) of Fig. 3 shows the kernel for the $\left\{\ln [\mathrm{HDO}]-\ln \left[\mathrm{H}_{2} \mathrm{O}\right]\right\}$-state. We call it the isotopologue ratio kernel $\left(\mathbf{A}_{\text {II }}^{\prime}\right)$. If we compare it with the upper left graph of panel (b), which represents the humidity kernel $\left(\mathbf{A}_{\mathrm{HH}}^{\prime}\right)$, we observe that the FTIR system resolves the vertical structures of humidity much finer than the respective isotopologue ratio structures (compare also the DOFS, which is 2.95 and 1.74 for $\mathbf{A}_{\mathrm{HH}}^{\prime}$ and $\mathbf{A}_{\mathrm{II}}^{\prime}$, respectively). This is rather unsatisfactory, since it means that our retrieved humidity and isotopologue ratio values are not representative of the same air mass. In order to assure the scientific usefulness of our water isotopologue product, we have to adapt the vertical resolution and sensitivity of the humidity product to the poorer vertical resolution and sensitivity of the isotopologue ratio product. This can easily be achieved by convolving the retrieved humidity profiles with the isotopologue ratio kernel $\left(\mathbf{A}_{\text {II }}^{\prime}\right)$, which is a valid operation since the humidity and isotopologue ratio are optimally estimated in an independent manner (according to Eq. (7), we introduce no a priori connection between the $\left\{\ln [\mathrm{HDO}]-\ln \left[\mathrm{H}_{2} \mathrm{O}\right]\right\}$-state and the $\left\{\left(\ln \left[\mathrm{H}_{2} \mathrm{O}\right]+\ln [\mathrm{HDO}]\right) / 2\right\}$-state $)$.

Panel (b) of Fig. 3 also indicates that there is a significant cross-dependence between the actual atmospheric humidity content and the retrieved isotopologue ratio. The respective kernel $\mathbf{A}_{\mathrm{HI}}^{\prime}$ is plotted as the bottom left graph. Please be aware that we scaled this kernel by a factor of $\frac{1.0}{0.08}=12.5$. 

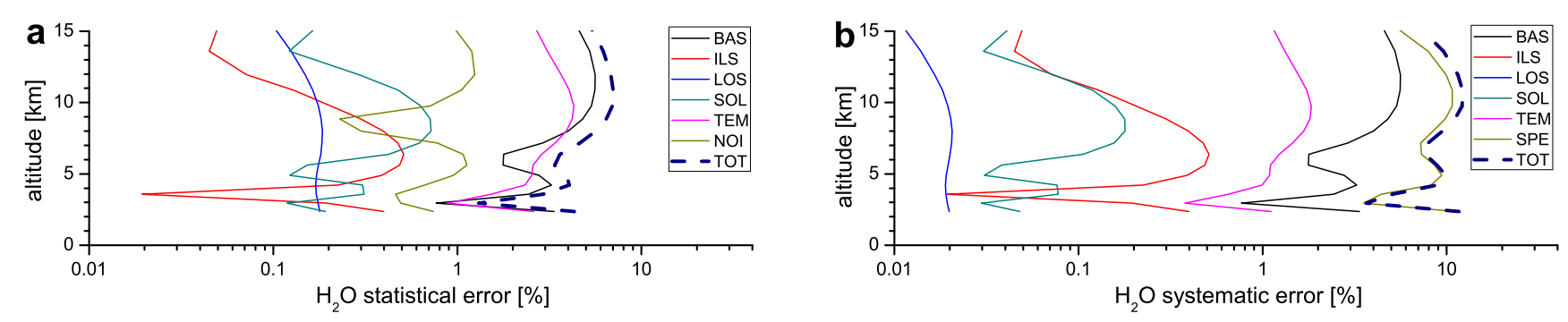

Fig. 5. $\mathrm{H}_{2} \mathrm{O}$ profile errors as estimated for Izaña from the uncertainty assumptions of Table 2 for the typical situation of 26 October 2011 . (a) statistical errors; (b) systematic errors. The acronyms in the legend correspond to the acronyms of Table 2; TOT represents the rootsquare-sum of all errors.

In this scale the kernels $\mathbf{A}_{\mathrm{HI}}^{\prime}$ and $\mathbf{A}_{\mathrm{II}}^{\prime}$ are directly comparable since it considers that the humidity variations are by more than one order of magnitude larger than the isotopologue ratio variations. We observe that the cross-dependence of $\delta \mathrm{D}$ on humidity and the remote sensing system's sensitivity of $\delta \mathrm{D}$ are of a similar magnitude, meaning that the error introduced by this retrieval artifact.

If we knew the real atmospheric humidity profile, we could a posteriori correct the cross-dependence. Alternatively, we can correct it approximatively by using the retrieved humidity instead of the real humidity. This is a valid operation since the retrieved humidity is not significantly affected by the isotopologue ratio (see the $\mathbf{A}_{\mathrm{IH}}^{\prime}$ kernel, represented in the upper right graph of panel (b)). This operation is equivalent to a two-step retrieval: in a first retrieval we estimate the humidity profile and in a second retrieval we estimate the isotopologue ratio whereby we fix the humidity to the values obtained by the first retrieval step.

Both operations, i.e. the adaption of the vertical resolution and sensitivity of the humidity profile and the correction of the cross-dependence, can be undertaken by a posteriori applying a matrix $\mathbf{C}$ to the retrieved variation of the $\left\{\left(\ln \left[\mathrm{H}_{2} \mathrm{O}\right]+\ln [\mathrm{HDO}]\right) / 2, \ln [\mathrm{HDO}]-\ln \left[\mathrm{H}_{2} \mathrm{O}\right]\right\}$-state vector:

$\mathbf{C}=\left(\begin{array}{cc}\mathbf{A}_{\mathrm{II}}^{\prime} & 0 \\ -\mathbf{A}_{\mathrm{HI}}^{\prime} & \mathbb{I}\end{array}\right)$.

The effect of this a posteriori operation can be visualised by contemplating the modified averaging kernel:

$$
\begin{aligned}
\mathbf{A}^{\prime \prime} & =\mathbf{C A}^{\prime} \\
& =\left(\begin{array}{cc}
\mathbf{A}_{\mathrm{II}}^{\prime} & 0 \\
-\mathbf{A}_{\mathrm{HI}}^{\prime} & \mathbb{I}
\end{array}\right)\left(\begin{array}{cc}
\mathbf{A}_{\mathrm{HH}}^{\prime} & \mathbf{A}_{\mathrm{IH}}^{\prime} \\
\mathbf{A}_{\mathrm{HI}}^{\prime} & \mathbf{A}_{\mathrm{II}}^{\prime}
\end{array}\right) \\
& =\left(\begin{array}{cc}
\mathbf{A}_{\mathrm{II}}^{\prime} \mathbf{A}_{\mathrm{HH}}^{\prime} & \mathbf{A}_{\mathrm{II}}^{\prime} \mathbf{A}_{\mathrm{IH}}^{\prime} \\
-\mathbf{A}_{\mathrm{HI}}^{\prime} \mathbf{A}_{\mathrm{HH}}^{\prime}+\mathbf{A}_{\mathrm{HI}}^{\prime} & -\mathbf{A}_{\mathrm{HI}}^{\prime} \mathbf{A}_{\mathrm{IH}}^{\prime}+\mathbf{A}_{\mathrm{II}}^{\prime}
\end{array}\right) \\
& =\left(\begin{array}{cc}
\mathbf{A}_{\mathrm{HH}}^{\prime \prime} & \mathbf{A}_{\mathrm{IH}}^{\prime \prime} \\
\mathbf{A}_{\mathrm{HI}}^{\prime \prime} & \mathbf{A}_{\mathrm{II}}^{\prime \prime}
\end{array}\right) .
\end{aligned}
$$

This kernel $\mathbf{A}^{\prime \prime}$ is shown in panel (c) of Fig. 3. We observe first, that the retrieved humidity and isotopologue ratio are now sensitive to the same atmospheric air mass (compare upper left and lower right graph), and second, that the cross- dependence of retrieved $\delta \mathrm{D}$ on atmospheric humidity variations is significantly reduced (see lower left graph).

\subsubsection{Sensitivity, vertical resolution, and cross-dependence on humidity}

The $\mathbf{A}_{\mathrm{HH}}^{\prime \prime}$ and $\mathbf{A}_{\mathrm{II}}^{\prime \prime}$ kernels as depicted in panel (c) of Fig. 3 reveal that we can distinguish the lower from the middle/upper tropospheric humidity and isotopologue state. According to Eqs. (8) and (9), we can use $\mathbf{A}_{\mathrm{HH}}^{\prime \prime}$ and $\mathbf{A}_{\mathrm{II}}^{\prime \prime}$ as proxies for the $\mathrm{H}_{2} \mathrm{O}$ and $\delta \mathrm{D}$ kernel, respectively.

Similarly to Eq. (11), we calculate the $\mathrm{H}_{2} \mathrm{O}$ and $\delta \mathrm{D}$ smoothing error covariance matrices $\left(\mathbf{S}_{\mathrm{sH}}^{\prime \prime}\right.$ and $\mathbf{S}_{\mathrm{sI}}^{\prime \prime}$, respectively) by

$\mathbf{S}_{\mathrm{sH}}^{\prime \prime}=\left(\mathbf{A}_{\mathrm{HH}}^{\prime \prime}-\mathbb{I}\right) \mathbf{S}_{\mathrm{aH}}\left(\mathbf{A}_{\mathrm{HH}}^{\prime \prime}-\mathbb{I}\right)^{T}$

and

$\mathbf{S}_{\mathrm{SI}}^{\prime \prime}=\left(\mathbf{A}_{\mathrm{II}}^{\prime \prime}-\mathbb{I}\right) \mathbf{S}_{\mathrm{aI}}\left(\mathbf{A}_{\mathrm{II}}^{\prime \prime}-\mathbb{I}\right)^{T}$.

The $\mathrm{H}_{2} \mathrm{O}$ smoothing error (square root values of the diagonal elements of $\mathbf{S}_{\mathrm{sH}}^{\prime \prime}$ ) significantly increases after applying the a posteriori operator $\mathbf{C}$ (compare black dotted line with black solid line in the upper panel of Fig. 4), since the vertical resolution of the humidity product has been reduced to the poorer resolution of the isotopologue ratio product. The total column smoothing error of $\mathrm{H}_{2} \mathrm{O}$ increases from $0.1 \%$ to $2.5 \%$ (compare Tables 3 and 4 ).

The black line in the bottom panel of Fig. 4 presents the $\delta \mathrm{D}$ smoothing error (square root values of the diagonal elements of $\left.\mathbf{S}_{\mathrm{sI}}^{\prime \prime}\right)$. The a priori uncertainty, i.e. the natural variability, of tropospheric $\delta \mathrm{D}$ is depicted as a thick blue dashed line. Up to an altitude of $8 \mathrm{~km}$, the FTIR measurement significantly reduces the a priori $\delta \mathrm{D}$ uncertainty. The red lines in this panel represent the error due to the cross-dependence of retrieved $\delta \mathrm{D}$ on real atmospheric humidity variations, i.e. the square root values of the error covariance matrix $\mathbf{S}_{\mathrm{cl}}^{\prime \prime}$ :

$\mathbf{S}_{\mathrm{cI}}^{\prime \prime}=\mathbf{A}_{\mathrm{HI}}^{\prime \prime} \mathbf{S}_{\mathrm{aH}} \mathbf{A}_{\mathrm{HI}}^{\prime \prime T}$.

The red solid and dotted lines visualise this error before and after applying the a posteriori operator $\mathbf{C}$ of Eq. (14). With the a posteriori correction, this error is about $2 \%$ in the 
Table 4. Same as Table 3 but after applying the a posteriori operator of Eq. (14).

\begin{tabular}{lrr}
\hline Error (acronym) & Statistical & Systematic \\
\hline NOI & $0.6 \%$ & - \\
BAS & $0.2 \%$ & $0.2 \%$ \\
ILS & $<0.1 \%$ & $<0.1 \%$ \\
TEM & $0.1 \%$ & $<0.1 \%$ \\
LOS & $0.2 \%$ & $<0.1 \%$ \\
SOL & $<0.1 \%$ & $<0.1 \%$ \\
SPE & - & $1.1 \%$ \\
Total (TOT) & $0.7 \%$ & $1.2 \%$ \\
Smoothing error & $2.5 \%$ & - \\
\hline
\end{tabular}

lower troposphere and $8 \%$ in the middle/upper troposphere, respectively (see red dashed line). This is a significant reduction if compared to the uncorrected state (not applying the a posteriori operator $\mathbf{C}$ ), where the respective error can reach $20 \%$ (see red solid line).

\subsubsection{Estimation of uncertainties}

The errors are calculated similar to Eq. (13) as the square root of the diagonal of the error covariance matrix $\mathbf{S}_{\mathrm{e}}^{\prime \prime}$ :

$\mathbf{S}_{\mathrm{e}}^{\prime \prime}=\mathbf{C P G K}_{p} \mathbf{S}_{p} \mathbf{K}_{p}^{T} \mathbf{G}^{T} \mathbf{P}^{T} \mathbf{C}^{T}$.

This means that we use the errors estimated for the $\left\{\left(\ln \left[\mathrm{H}_{2} \mathrm{O}\right]+\ln [\mathrm{HDO}]\right) / 2\right\}$-state as proxies for $\mathrm{H}_{2} \mathrm{O}$ errors and the errors estimated for the $\left\{\ln [\mathrm{HDO}]-\ln \left[\mathrm{H}_{2} \mathrm{O}\right]\right\}$-state as conservative proxies for $\delta \mathrm{D}$ errors. According to Eqs. (8) and (9), these approximations are well justified.

Figure 6 presents the estimated errors (upper panels for $\mathrm{H}_{2} \mathrm{O}$, lower panels for $\left.\delta \mathrm{D}\right)$. The calculations result from the uncertainty sources of Table 2. Measurement noise as well as uncertainties in the tropospheric temperature structure and the baseline dominate the random error of $\mathrm{H}_{2} \mathrm{O}$ and $\delta \mathrm{D}$. The systematic errors are clearly controlled by uncertainties in the spectroscopic line parameters, which can give rise to a $\delta \mathrm{D}$ error of $100-200 \%$. The respective column integrated errors are listed in Tables 4 and 5.

The Figs. 5 and 6 depict the error profiles for the typical measurement of Fig. 2. However, it is important to remark that the structure of these error profiles varies for different measurement situations according to the respective sensitivity of the remote sensing system. In order to demonstrate this, we examine the behavior of an error caused by a systematic uncertainty of the spectroscopic line parameters. For the typical measurement of Fig. 2 and for the a posteriori corrected dataset, this error has a minimum at $4 \mathrm{~km}$ (see panel (b) of Fig. 6), which is actually due to the fact the error typically changes its sign at this altitude (for our uncertainty assumptions, it is negative below and positive above $4 \mathrm{~km}$ ). In Fig. 7 we depict the error at $4 \mathrm{~km}$ for the about 2150 observations made at Izaña since 1999. We observe that this error - caused
Table 5. Same as Table 4 but for $\delta \mathrm{D}$ and with smoothing error as well as error due to cross-dependence on humidity.

\begin{tabular}{|c|c|c|}
\hline Error (acronym) & Statistical & Systematic \\
\hline NOI & $1.4 \%$ & - \\
\hline BAS & $5.9 \%$ & $5.9 \%$ \\
\hline ILS & $<0.1 \%$ & $<0.1 \% \circ$ \\
\hline TEM & $3.2 \% 0$ & $1.2 \% 0$ \\
\hline LOS & $<0.1 \%$ & $<0.1 \%$ \\
\hline SOL & $<0.1 \% \circ$ & $<0.1 \%$ o \\
\hline SPE & - & $22.4 \%$ \\
\hline Total (TOT) & $6.9 \%$ & $23.3 \%$ \\
\hline Cross-dep. on hum. & $0.3 \%$ & - \\
\hline Smoothing error & $2.0 \%$ & - \\
\hline
\end{tabular}

by a systematic line parameter uncertainty - is not constant, instead it depends on the vertical structure that can be observed by the remote sensing system. As a measure for this structure, we use the ratio between the DOFS values for the lower and the middle/upper troposphere (DOFS below and above $4 \mathrm{~km}$ ). If this ratio is larger than unity, i.e. if the observing system is more sensitive with respect to the lower than to the middle/upper troposphere, the zero-crossing of the error is below $4 \mathrm{~km}$ and the error at $4 \mathrm{~km}$ is positive, and vice versa (if the ratio is smaller than unity, the zero-crossing is above $4 \mathrm{~km}$ and the error at $4 \mathrm{~km}$ is negative).

\subsubsection{A posteriori processing}

The remote sensing technique retrieves the tropospheric $\left\{\ln \left[\mathrm{H}_{2} \mathrm{O}\right], \ln [\mathrm{HDO}]\right\}$-state, from which we calculate the tropospheric $\mathrm{H}_{2} \mathrm{O}$ and $\delta \mathrm{D}$ values. As explained in the previous sections, these $\mathrm{H}_{2} \mathrm{O}$ and $\delta \mathrm{D}$ data can be well characterised in the $\left\{\left(\ln \left[\mathrm{H}_{2} \mathrm{O}\right]+\ln \left[\mathrm{H}_{2} \mathrm{O}\right]\right) / 2, \ln [\mathrm{HDO}]-\ln \left[\mathrm{H}_{2} \mathrm{O}\right]\right\}$-basis In this basis we can also perform the a posteriori correction of the originally retrieved $\left\{\ln \left[\mathrm{H}_{2} \mathrm{O}\right], \ln [\mathrm{HDO}]\right\}$-state $(\hat{\boldsymbol{x}})$. The corrected $\left\{\ln \left[\mathrm{H}_{2} \mathrm{O}\right], \ln [\mathrm{HDO}]\right\}$-state $\left(\hat{\boldsymbol{x}}^{*}\right)$ is obtained by a simple matrix multiplication applying the matrices $\mathbf{P}$ and $\mathbf{C}$ of Eqs. (6) and (14):

$\hat{\boldsymbol{x}}^{*}=\mathbf{P}^{-1} \mathbf{C P}\left(\hat{\boldsymbol{x}}-\boldsymbol{x}_{\mathrm{a}}\right)+\boldsymbol{x}_{\mathrm{a}}$.

Subsequently, we calculate the corrected tropospheric $\mathrm{H}_{2} \mathrm{O}$ and $\delta \mathrm{D}$ values from the corrected $\left\{\ln \left[\mathrm{H}_{2} \mathrm{O}\right], \ln [\mathrm{HDO}]\right\}$-state $\left(\hat{\boldsymbol{x}}^{*}\right)$.

This a posteriori correction assures that the $\mathrm{H}_{2} \mathrm{O}$ and $\delta \mathrm{D}$ products represent the same atmospheric air mass, which is essential in order to correctly exploit the added value of the $\delta \mathrm{D}$ observations. Furthermore, it guarantees that the crossdependence of retrieved $\delta \mathrm{D}$ on atmospheric humidity variations is minimised. This cross-dependence might lead to an erroneous correlation between $\mathrm{H}_{2} \mathrm{O}$ and $\delta \mathrm{D}$. However, it is mainly this correlation that provides the added scientific value. If the correlation between the retrieved $\mathrm{H}_{2} \mathrm{O}$ and $\delta \mathrm{D}$ product were mainly due to the cross-dependence 

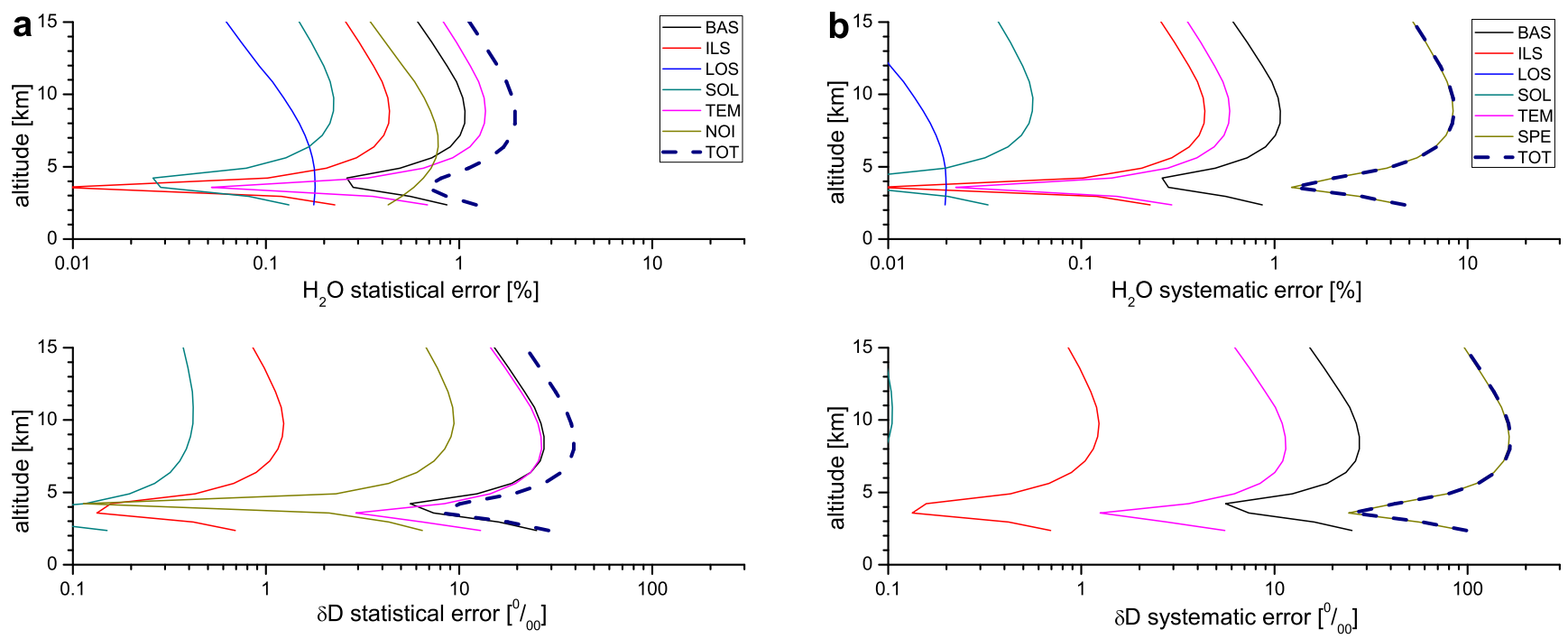

Fig. 6. Same as Fig. 5 but for $\mathrm{H}_{2} \mathrm{O}$ (top panels) as well as $\delta \mathrm{D}$ (bottom panels) and after applying the a posteriori operator of Eq. (14).
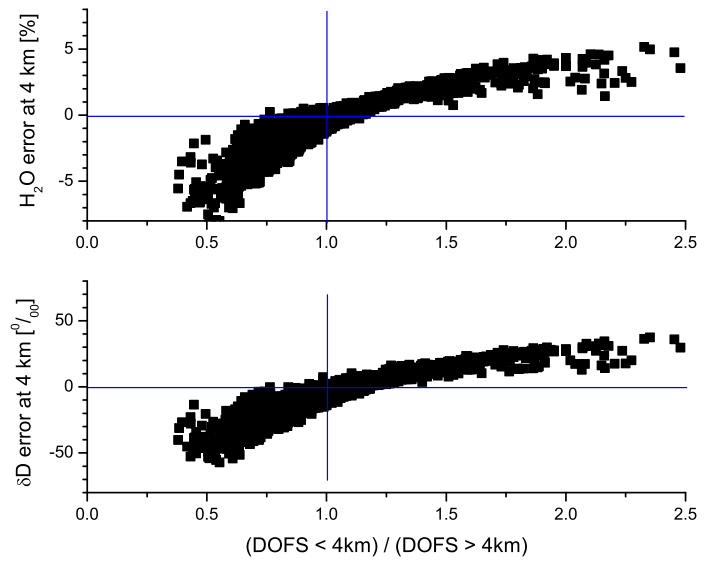

Fig. 7. Error response at $4 \mathrm{~km}$ of a systematic spectroscopic line parameter uncertainty to the vertical sensitivity of the remote sensing system at Izaña (expressed by the ratio between the DOFS values for the lower and the middle/upper troposphere). Top panel: $\mathrm{H}_{2} \mathrm{O}$; bottom panel: $\delta \mathrm{D}$.

of retrieved $\delta \mathrm{D}$ on humidity and not representative for the actual atmospheric correlation between $\mathrm{H}_{2} \mathrm{O}$ and $\delta \mathrm{D}$, the observational isotopologue data would not provide significant additional information about the atmospheric water vapour state. Then both the retrieved $\mathrm{H}_{2} \mathrm{O}$ and $\delta \mathrm{D}$ would mainly reflect atmospheric $\mathrm{H}_{2} \mathrm{O}$ variability.

\subsection{Summary for the whole network}

The sensitivity, vertical resolution, and errors as estimated in Sects. 4.1 and 4.2 for a typical Izaña measurement are well representative of the whole network. In order to demonstrate this, we present statistics of the sensitivity, vertical resolution, and estimated errors for all the ten stations. These
Table 6. Statistics of the DOFS and the current data record for the ten ground-based MUSICA sites.

\begin{tabular}{lccc}
\hline Site & $\begin{array}{c}\text { DOFS for } \mathrm{H}_{2} \mathrm{O}, \text { Sect. 4.1 } \\
\text { (for isotopologues, Sect. 4.2) }\end{array}$ & $\begin{array}{c}\text { Number } \\
\text { of obs. }\end{array}$ & $\begin{array}{c}\text { First } \\
\text { year }\end{array}$ \\
\hline EU & $2.7(1.6)$ & 1555 & 2006 \\
NA & $2.5(1.6)$ & 278 & 2005 \\
KI & $2.5(1.5)$ & 1526 & 1996 \\
BR & $2.4(1.2)$ & 411 & 2004 \\
KA & $2.5(1.6)$ & 925 & 2010 \\
JJ & $2.8(1.7)$ & 1924 & 1996 \\
IZ & $2.9(1.7)$ & 2147 & 1999 \\
WO & $2.5(1.2)$ & 3084 & 2007 \\
LA & $2.6(1.2)$ & 1999 & 1997 \\
AH & $2.7(1.5)$ & 285 & 2002 \\
\hline
\end{tabular}

statistics are obtained from the individual characterisation of all available ground-based MUSICA observations. Table 6 gives a brief overview of the considered data volume. The table also summarizes the mean DOFS values obtained at the different stations.

Concerning the retrieved $\mathrm{H}_{2} \mathrm{O}$ profiles, the mean DOFS is above 2.4 for all stations and very close to 3 for the high-altitude stations Jungfraujoch and Izaña. Figure 8 shows mean $\mathrm{H}_{2} \mathrm{O}$ profile errors. It is a summary for the whole network of the detailed estimation presented in Sect. 4.1 for a typical Izaña measurement. The left plot of panel (a) shows that the estimated mean smoothing error is, at all stations and up to an altitude of $7 \mathrm{~km}$, smaller than $50 \%$. This is a significant reduction of the a priori uncertainty, which is as large as $100 \%$. It documents the good sensitivity of the remote sensing systems within this altitude range. For the high-altitude stations Jungfraujoch and Izaña, the smoothing 

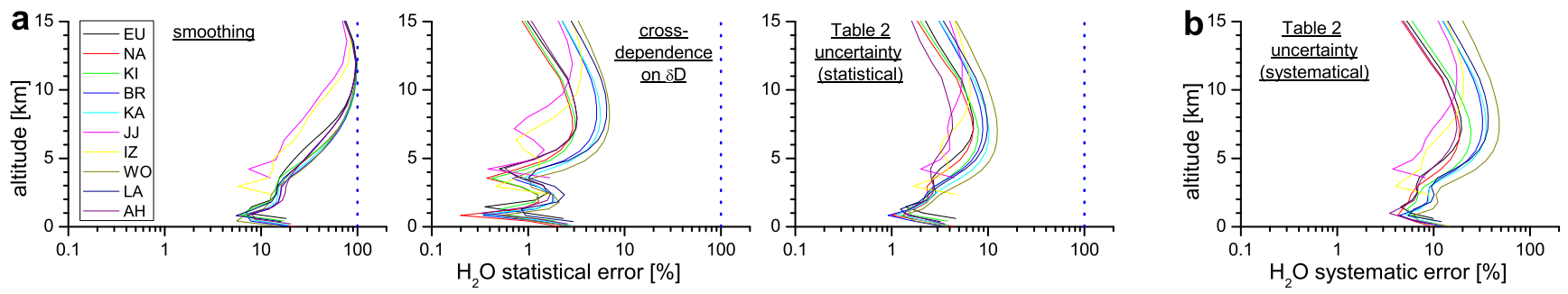

Fig. 8. Mean $\mathrm{H}_{2} \mathrm{O}$ profile errors as estimated for the ten stations participating in MUSICA. (a) statistical errors, from the left to the right for smoothing, cross-dependence, and due to the uncertainty assumptions of Table 2. (b) systematic errors for the parameter uncertainty assumptions of Table 2 . The blue dashed line indicates the natural variability.
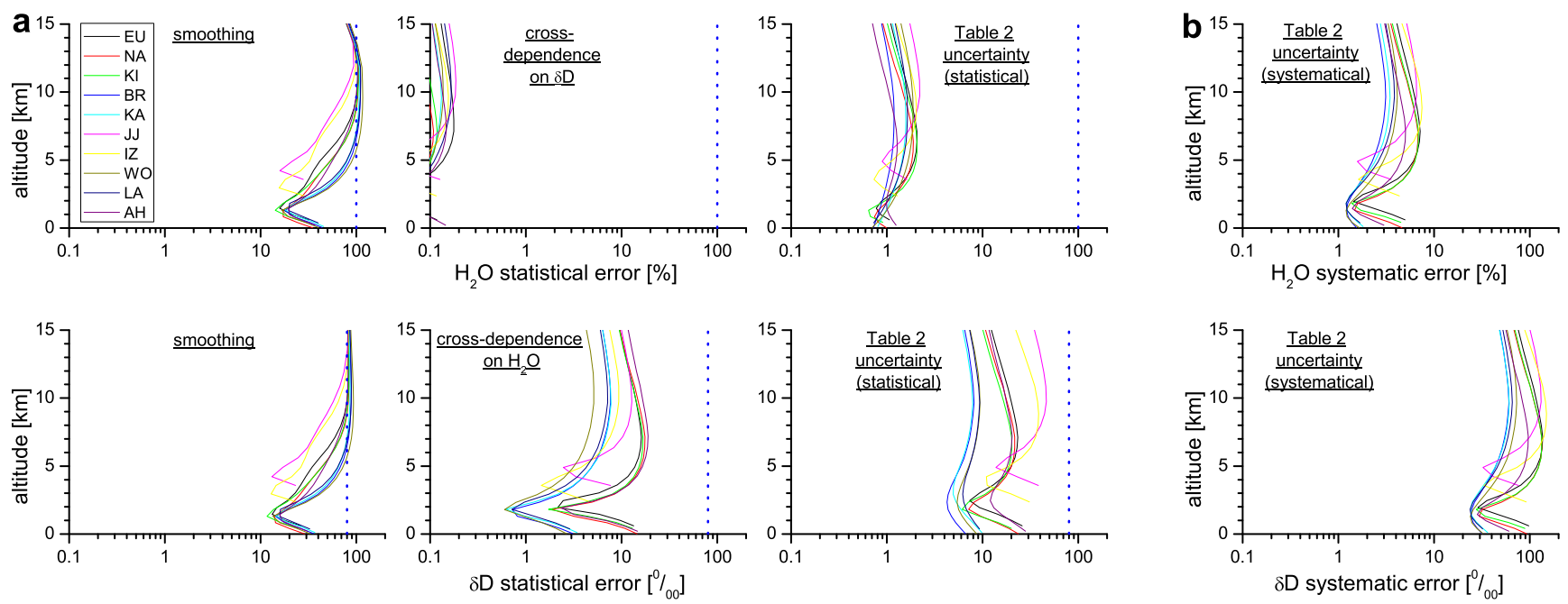

Fig. 9. Same as Fig. 8 but for $\mathrm{H}_{2} \mathrm{O}$ (top plots) as well as $\delta \mathrm{D}$ (bottom plots) and after applying the a posteriori operator of Eq. (14).

error is smaller than $50 \%$, even up to $10 \mathrm{~km}$. Compared to this good sensitivity, the error due to cross-dependence on atmospheric $\delta \mathrm{D}$ variations can be neglected (central plot of panel (a)). The right plot of panel (a) depicts the mean total errors as estimated for the statistical uncertainty sources of Table 2. This error is smaller than $10 \%$ for all stations and throughout the troposphere. Panel (b) shows the mean total error estimations for the systematic uncertainty sources of Table 2. As documented in panel (b) of Fig. 5, this total error is dominated by an uncertainty in the applied spectroscopic line parameters.

The mean DOFS obtained for the retrieval of the isotopologue state (consistent $\mathrm{H}_{2} \mathrm{O}$ and $\delta \mathrm{D}$ profiles) ranges between 1.2 for humid low-altitude sites and 1.7 for high-altitude sites (see values in brackets of Table 6). The mean errors are depicted in Fig. 9. This figure is a summary for the whole network of the detailed estimation presented in Sect. 4.2 for a typical Izaña measurement. We observe that the errors are quite similar for the different stations. The error due to the cross-dependence of $\delta \mathrm{D}$ on humidity is below $15 \%$ for all stations and at all levels. This value is acceptable but it is important to remark that it can only be achieved by the a poste- riori processing as suggested by Eq. (20). Not correcting the cross-dependence would cause errors of about $35 \%$.

The mean errors of the total column-integrated data are very similar for all stations and very close to the values listed in Tables 3, 4, and 5.

\section{The network-wide data consistency}

The solar absorption mid-infrared spectra recorded by the NDACC-FTIR instruments at high spectral resolution contain absorption signatures of many different atmospheric species. The amounts retrieved for long-lived and thus globally well-mixed species can be used to examine the networkwide consistency of the data produced within the FTIR network.

Atmospheric $\mathrm{CO}_{2}$ is a long-lived trace gas with useful absorption signatures in the middle infrared. However, we have to consider the seasonal cycles and latitudinal gradients of $\mathrm{CO}_{2}$ (atmospheric $\mathrm{CO}_{2}$ sources and sinks vary with season, and the anthropogenic sources are mainly in the Northern Hemisphere). Deseasonalising can remove the site dependent seasonal cycles but not the latitudinal gradients. The largest 


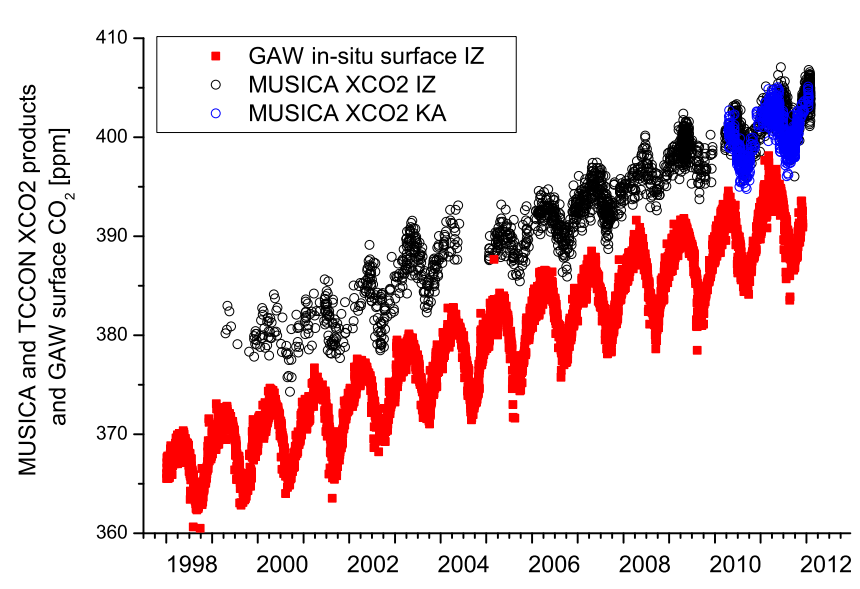

Fig. 10. Time series of XCO2 data obtained from the mid-infrared spectra recorded at Izaña (black circles) and Karlsruhe (blue circles). For comparison, the Global Atmospheric Watch (GAW) Izaña surface in-situ $\mathrm{CO}_{2}$ observations are shown (red squares).

differences in the deseasonalised near-surface $\mathrm{CO}_{2}$ concentrations occur between the $30^{\circ} \mathrm{N}-60^{\circ} \mathrm{N}$ and the $60^{\circ} \mathrm{S}-90^{\circ} \mathrm{S}$ belt (5-6 ppmv, e.g. Fig. 3.4a of the WDCGG-GAW 2012 summary, http://ds.data.jma.go.jp/gmd/wdcgg/pub/products/ summary/sum36/sum36contents.html). Concerning columnaveraged $\mathrm{CO}_{2}(\mathrm{XCO} 2)$ the latitudinal gradients are smaller. Reuter et al. (2012) report differences in deseasonalised annual means obtained at northern and southern hemispheric TCCON (Total Carbon Column Observing Network) stations of about 2-3 ppmv (see their Fig. 4). The smaller latitudinal gradients in $\mathrm{XCO} 2$, if compared to near-surface $\mathrm{CO}_{2}$, might be explained as follows: first, the northern hemispheric $\mathrm{CO}_{2}$ net emission (anthropogenic sources) as well as the southern hemispheric $\mathrm{CO}_{2}$ net absorption (by the oceans) affects nearsurface $\mathrm{CO}_{2}$ stronger than free tropospheric $\mathrm{CO}_{2}$ and $\mathrm{XCO} 2$. Second, the $\mathrm{CO}_{2}$ transport between the hemispheres occurs mainly in the free troposphere, i.e. anthropogenic $\mathrm{CO}_{2}$ emitted in the Northern Hemisphere arrives first to the southern hemispheric free troposphere and is then transported downward through vertical mixing. Thus, inter-hemispheric transport affects XCO2 more directly than near-surface $\mathrm{CO}_{2}$.

Consequently and taking into account the $6 \%$ difference between the Southern and Northern Hemisphere, we can use deseasonalised annual mean $\mathrm{XCO} 2$ as a reference for documenting the network-wide data consistency.

\subsection{Column-averaged $\mathrm{CO}_{2}(\mathrm{XCO})$ retrievals in the mid-infrared}

For MUSICA we perform a XCO2 retrieval using the same spectra that are used for the water isotopologue retrieval. Therefore, we use four spectral $\mathrm{CO}_{2}$ windows between 2620 and $2630 \mathrm{~cm}^{-1}$ (Kohlhepp, 2007). Figure 10 shows an example of our MUSICA XCO2 time series for Izaña and Karlsruhe. For comparison, we also depict the Izaña GAW

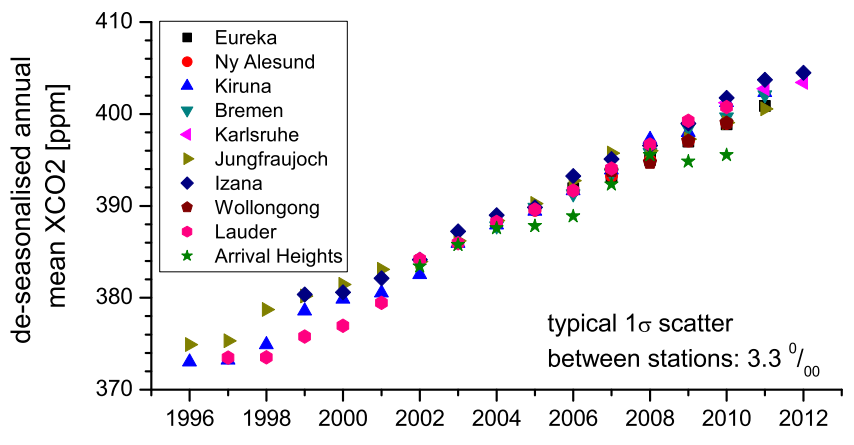

Fig. 11. Deseasonalised annual mean MUSICA XCO2 product as retrieved at the ten NDACC stations of Fig. 1. The typical $1 \sigma$ scatter between stations is the typical standard deviation of the deseasonalised annual mean measured at the different stations for the same year.

(Global Atmospheric Watch) nighttime surface in-situ data. At the subtropical mountain observatory of Izaña, these GAW surface data are well representative for the tropospheric column-averaged amounts (Sepúlveda et al., 2012). We observe that the mid-infrared $\mathrm{XCO} 2$ data obtained at Izaña and Karlsruhe are very consistent and that their annual cycles and long-term trends are very similar to the ones observed in the GAW data. This documents the excellent quality of the mid-infrared MUSICA XCO2 data.

\subsection{Agreement between all MUSICA stations}

Figure 11 depicts the time series of deseasonalised annual mean mid-infrared $\mathrm{XCO} 2$ for the ten MUSICA stations. Between 1996 and 2012, the $1 \sigma$ scatter of the deseasonalised annual mean measured at the different stations for the same year is on average $3.3 \%$, thereby documenting the excellent network-wide data consistency. Please note that we can even observe the aforementioned small latitudinal gradient in XCO2: the southern hemispheric sites (Wollongong, Lauder, and Arrival Heights) tend to detect a few per mill less XCO2 than the northern hemispheric sites.

Figure 11 is a proof of the excellent work by the many different technicians, $\mathrm{PhD}$ students, post-docs, and scientists from the different research groups that have been involved in the NDACC-FTIR activities during the last two decades.

Furthermore and assuming that a significant part of the remaining inconsistency is due to an uncertainty in the ILS (probably not all FTIR spectrometer are optimally aligned), this consistency estimation tends to be conservative for $\mathrm{H}_{2} \mathrm{O}$. The reason is that the upper tropospheric and stratospheric concentrations of the reference absorber $\mathrm{CO}_{2}$ cannot be neglected and consequently the retrieved $\mathrm{XCO} 2$ is more strongly affected by an ILS uncertainty than the retrieved tropospheric $\mathrm{H}_{2} \mathrm{O}$. 

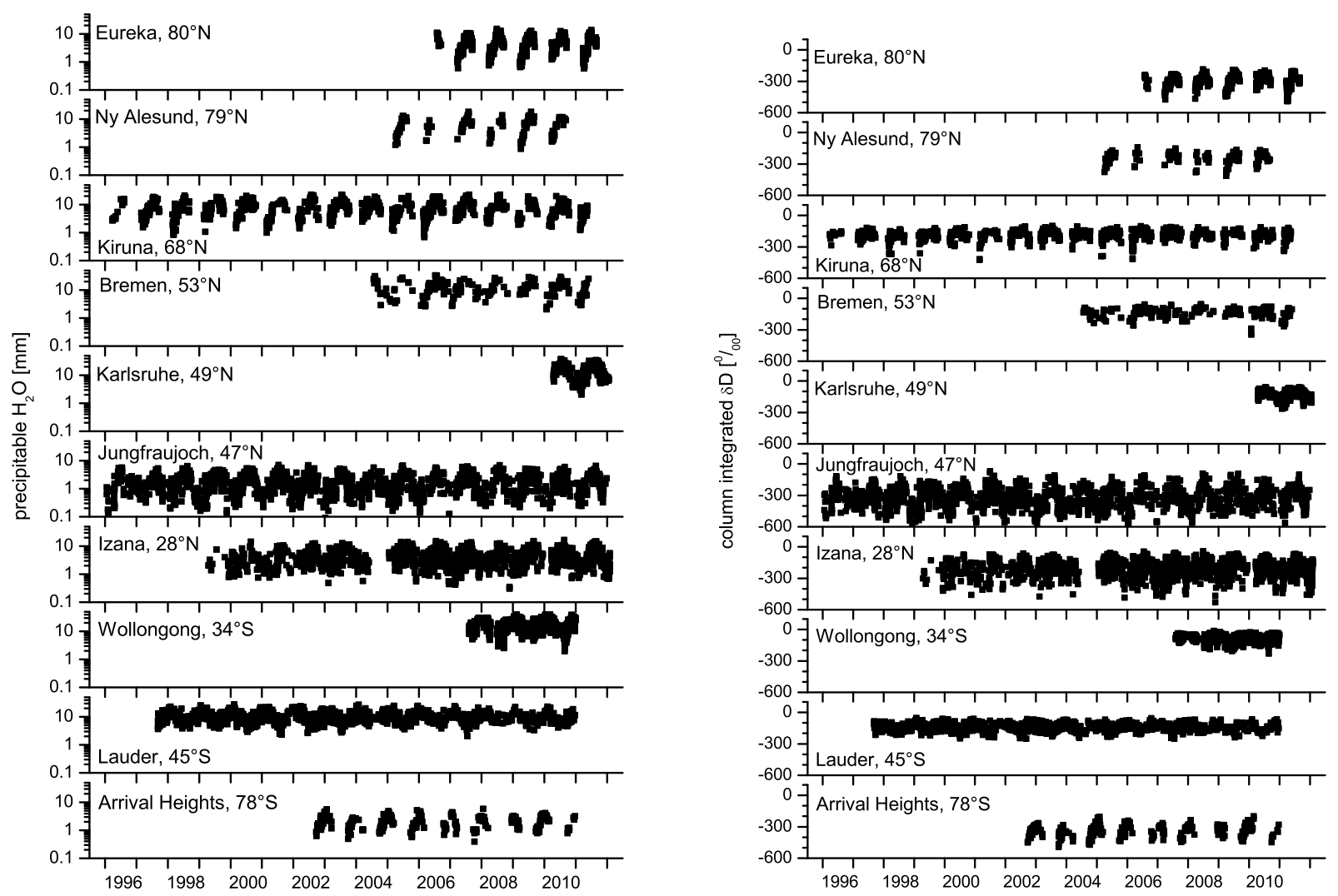

Fig. 12. Time series of column integrated $\mathrm{H}_{2} \mathrm{O}$ (left panel) and $\delta \mathrm{D}$ (right panel) as currently available at the ten ground-based remote sensing sites that participate in MUSICA.

\section{A tropospheric water vapour isotopologue climatology}

The main focus of this paper is to give a better insight into the complexity of the water vapour isotopologue remote sensing data. This has been extensively addressed in the previous sections. In this section, we present the first ground-based MUSICA water vapour isotopologue climatology and compare it to simulations of an isotope-incorporated AGCM. Although a detailed scientific discussion would be outside the scope of this paper, we think that it is very useful to show a practical example of applying this unique long-term dataset for atmospheric water cycle research.

We dedicate special care to correctly present the uncertainty levels of the observational reference data. It is important to recall that remote sensing of scientifically useful isotopologue data is very difficult and the errors have complex characteristics. Consequently, the careful error treatment as performed in the first part of this paper is indispensable for correctly interpreting the model-measurement differences (we use here the a posteriori corrected data according to Eq. 20). We focus on large-scale processes and examine annual and monthly climatologies.

\subsection{Available observational data}

Figure 12 gives an overview of the currently available MUSICA ground-based remote sensing data. In total, the dataset consists of almost 15000 individual observations (see also brief statistics of Table 6). At some stations (e.g. Wollongong or Karlsruhe) observations are made during the entire day if the weather conditions are fine, leading to a high number of observations. For the polar sites, there are no winter observations, since the FTIR technique needs the solar light beam, which is not available during polar night.

The whole dataset will be made available to the scientific community via an FTP server in HDF format in the following months.

\subsection{The model IsoGSM}

IsoGSM is an isotope incorporated AGCM based on an upto-date version of the Scripps Experimental Climate Prediction Center's Global Spectral Model (ECPC's GSM; Kanamitsu et al., 2002). IsoGSM can be nudged towards NCEP (National Centers for Environmental Prediction) reanalysis large scale horizontal wind and temperature fields (Yoshimura and Kanamitsu, 2008). This is important when comparing the model to measurements, since tropospheric 

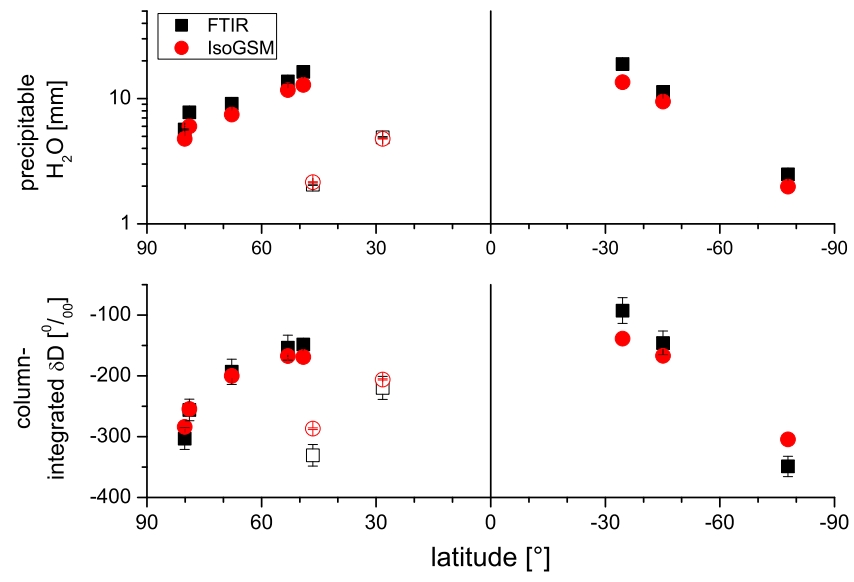

Fig. 13. Multi-year mean of column-integrated data versus latitude. Upper panel: total precipitable water vapour; bottom panel: columnintegrated $\delta \mathrm{D}$. Black squares: FTIR data; red dots: IsoGSM simulations. The values from high-altitude stations are distinguished by open symbols.

water vapour and its isotopic composition vary strongly with the actual synoptic situation. The nudging technique adjusts the model dynamics to the actual short-term synoptic-scale situation and allows an adequate simulation of day-to-day as well as inter-annual variabilities. Please note that water vapour is not nudged, i.e. the model retains its own hydrological cycle. The horizontal resolution of the model is T62 (about $200 \mathrm{~km}$ ), and the vertical resolution is 28 sigma-level layers. The output is 17 pressure-level grid points, i.e. 1000, $925,850,700,600,500,400,300,250,200,150,100,70$, $50,30,20$, and $10 \mathrm{hPa}$. For more details please refer to (Yoshimura et al., 2008). The model data are available on a global scale since 1979 with a temporal resolution of $6 \mathrm{~h}$.

\subsection{Annual climatology}

Figure 13 shows the multi-year means of total precipitable water vapour and column integrated $\delta \mathrm{D}$ for the different stations. The error bars are the root-square-sum of the $1 \sigma$ error of the multi-year mean and the errors are as estimated in the first part of this manuscript. For the low-altitude stations, we observe a clear latitude dependence. Both total water vapour content as well as $\delta \mathrm{D}$ is lowest at high latitudes and highest at low latitudes. At low latitudes, the atmospheric water mass is close to its dominating source region (the subtropical/tropical ocean) and atmospheric temperatures are relatively high so that the water has experienced relatively few condensation events. As a consequence the water vapour content is high and the HDO depletion remains low (high $\delta$ D). During transport to higher latitudes, the temperatures get lower and the water mass becomes saturated and condenses (equilibrium condensation), which consecutively removes water from the vapour phase. Since the heavy water isotopologues condense preferably, the remaining vapour

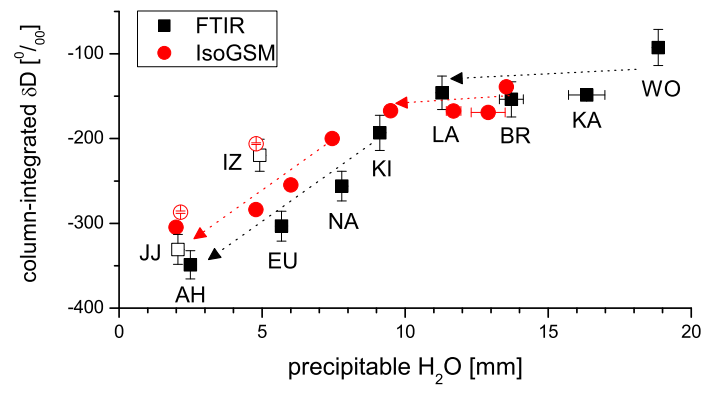

Fig. 14. Plot of multi-year mean column-integrated $\delta \mathrm{D}$ versus multiyear mean total precipitable water vapour. Station acronyms are given at each data point. Black squares: FTIR data; red dots IsoGSM simulations. The dashed black and red arrows indicate the typical $\delta \mathrm{D}-\mathrm{H}_{2} \mathrm{O}$ distribution of the FTIR and IsoGSM data, respectively. The values from high-altitude stations are distinguished by open symbols.

becomes increasingly more HDO depleted (low $\delta \mathrm{D}$ ). Consecutive condensation can also explain the low total vapour content and column integrated $\delta \mathrm{D}$ at the high-altitude station (Jungfraujoch and Izaña, marked by open symbols).

In order to assure that the model represents data for the same airmass as the FTIR system, we smoothed the model data with the FTIR averaging kernel. We observe a significant dry bias of the modeled with respect to the measured total precipitable water vapour of about $25 \%$. This dry bias is observed at high as well as low latitudes. However, it is limited to the lower troposphere (Schneider et al., 2010b) and therefore, it is not observed at the high-altitude stations. On the other hand and concerning $\delta \mathrm{D}$, the difference between measurement and simulation is site-dependent. We observe a positive systematic difference in column-integrated $\delta \mathrm{D}$ (IsoGSM-FTIR) at high-latitude and high-altitude stations (the dry stations) and a negative bias at the lower latitude stations (the humid stations). Taking the FTIR data as the reference, the model underestimates $\delta \mathrm{D}$ close to the humidity source region (low altitude/latitude sites) and overestimates $\delta \mathrm{D}$ far away from the humidity source regions (high altitude/latitude sites). This characteristic of the measurementmodel difference can be well observed in the " $\mathrm{H}_{2} \mathrm{O}-\delta \mathrm{D}$ " plot of Fig. 14.

\subsection{Monthly climatology}

In this subsection we examine the typical annual cycle of the water vapour isotopologues. Panel (a) of Fig. 15 depicts all the observations available for Izaña for the 1999-2012 time period (about 2150 observations). As an example we look here at column integrated data. The two left plots show the multi-year annual cycles (all observations made in the different years are gathered in one annual plot). We observe that there is a large day-to-day variability. The annual cycles can be better visualised by calculating the monthly averages. 

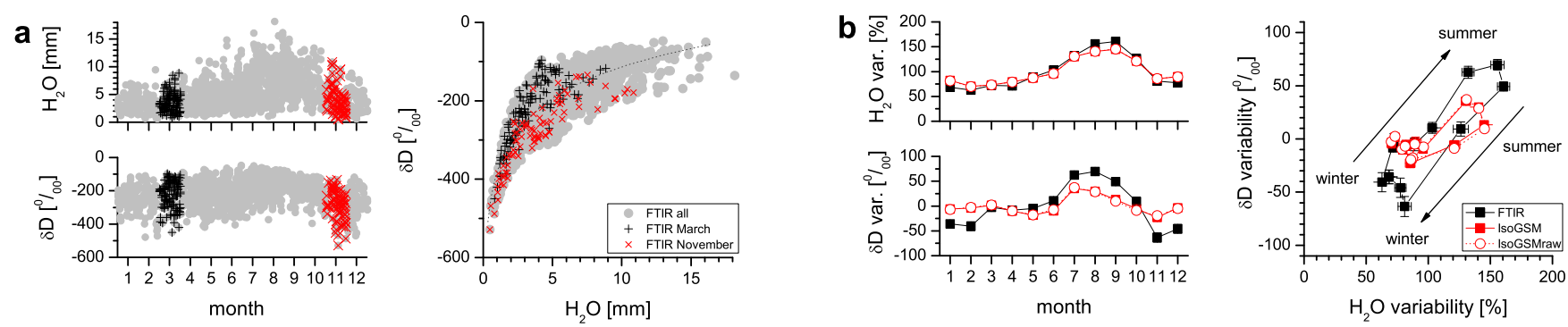

Fig. 15. Multi-year annual cycles of column-integrated $\mathrm{H}_{2} \mathrm{O}$ and $\delta \mathrm{D}$ as observed by the ground-based FTIR system at Izaña. (a) all observations (all March and all November observations are highlighted by black and red crosses, respectively); (b) intra-annual variability of monthly averages (black: FTIR observations; red solid squares: IsoGSM simulations smoothed by FTIR kernels; red circles: unsmoothed IsoGSM simulations).

The two left graphs of panel (b) depict the intra-annual variability of these monthly averages (black solid squares). In case of $\mathrm{H}_{2} \mathrm{O}$ (upper plot), it is the monthly average value relative to the multi-year $\mathrm{H}_{2} \mathrm{O}$ mean, and in case of $\delta \mathrm{D}$ (lower plot), it is the monthly $\delta \mathrm{D}$ averages minus the multi-year $\delta \mathrm{D}$ mean (the multi-year means are presented in Fig. 13). The error bar for each monthly average data point is the rootsquare-sum of the $1 \sigma$ error of the monthly average and the errors as estimated in the first part of this manuscript. They are depicted in the plots of panel (b) but often rather small and thus hardly visible.

We observe very significant annual cycles for both $\mathrm{H}_{2} \mathrm{O}$ and $\delta \mathrm{D}$. Total precipitable water reaches its maximum during the second half of summer (August/September). The amplitude of the cycle is about $100 \%$ (intra-annual variability value varies between 50 and $150 \%$ ). The column-integrated $\delta \mathrm{D}$ values are highest in the beginning of summer (July) and the amplitude is about $100 \%$ o (intra-annual variability values of $-50 \%$ in winter and $+50 \%$ in summer).

The right graphs of panel (a) and (b) show $\mathrm{H}_{2} \mathrm{O}-\delta \mathrm{D}$ plots. It documents the added value of $\delta \mathrm{D}$ observations if performed together with $\mathrm{H}_{2} \mathrm{O}$. We find that in March and November, the humidity levels in the atmosphere above Izaña are very similar, but that the isotopic compositions are significantly different: in November the water vapour mass is much more depleted in HDO if compared to March. The actual situation becomes clearly visible by looking on the $\mathrm{H}_{2} \mathrm{O}-$ $\delta \mathrm{D}$ plot of the intra-annual variability (right graph of panel (b)): passing from summer to winter, the troposphere is more depleted in heavy isotopologues than passing from winter to summer, i.e. spring and autumn humidity has different isotopic fingerprints.

In addition to the FTIR data (black solid squares), panel (b) of Fig. 15 depicts the intra-annual variability as simulated by the model IsoGSM: red solid squares are for model data smoothed by the FTIR's averaging kernels (see Fig. 3) and red circles are for unsmoothed model data. Since here we look on averages of many hundreds of individual observations, the difference between smoothed and unsmoothed model data is rather small (the averaging works similarly to the smoothing). Like the measurement, the model reveals that there is a difference in the isotopic composition of spring and autumn humidity. However, in the model the differences between the winter-to-summer and the summer-towinter transitions are much weaker than in the observational dataset. Furthermore, the model significantly underestimates the amplitude of the annual cycle of $\delta \mathrm{D}$.

Figure 16 shows $\mathrm{H}_{2} \mathrm{O}-\delta \mathrm{D}$ plots of the intra-annual variability for all ten sites that participate in MUSICA (lower as well as middle tropospheric and middle as well as upper tropospheric data for the low- and high-altitude sites, respectively). The model IsoGSM captures some of the differences between the different sites, e.g. the relatively low $\mathrm{H}_{2} \mathrm{O}$ and $\delta \mathrm{D}$ variability at the two southwestern Pacific sites Wollongong and Lauder compared to the other sites. For most sites, the FTIR dataset reveals significant differences between the summer-to-winter and winter-to-summer transition. For the Arctic sites (Eureka, Ny Ålesund, and Kiruna), this kind of annual cycle is especially pronounced in the middle troposphere. At the high-altitude site of Jungfraujoch, it is more pronounced in the middle than in the upper troposphere. To some extent these observations become visible in the simulations, e.g. for Kiruna the model simulates a slight difference between the summer-to-winter and winter-to-summer transition for the middle but not for the lower troposphere. However, at the aforementioned sites the modeled and measured annual $\mathrm{H}_{2} \mathrm{O}-\delta \mathrm{D}$ cycles generally disagree, whereby the disagreement cannot be explained by the uncertainty in the observational dataset. On the contrary for other sites, like Bremen or Karlsruhe, the measured and modeled $\mathrm{H}_{2} \mathrm{O}-\delta \mathrm{D}$ plots agree within the estimated uncertainties.

\section{Conclusions}

This paper presents a method for characterising the $\mathrm{H}_{2} \mathrm{O}$ and $\delta \mathrm{D}$ remote sensing datasets. The method consists in transferring the retrieved $\left\{\ln \left[\mathrm{H}_{2} \mathrm{O}\right], \ln [\mathrm{HDO}]\right\}$-state onto a basis that is well representative of the $\mathrm{H}_{2} \mathrm{O}$ and $\delta \mathrm{D}$ state: the $\left\{\left(\ln \left[\mathrm{H}_{2} \mathrm{O}\right]+\ln [\mathrm{HDO}]\right) / 2, \ln [\mathrm{HDO}]-\ln \left[\mathrm{H}_{2} \mathrm{O}\right]\right\}$-basis. In this 


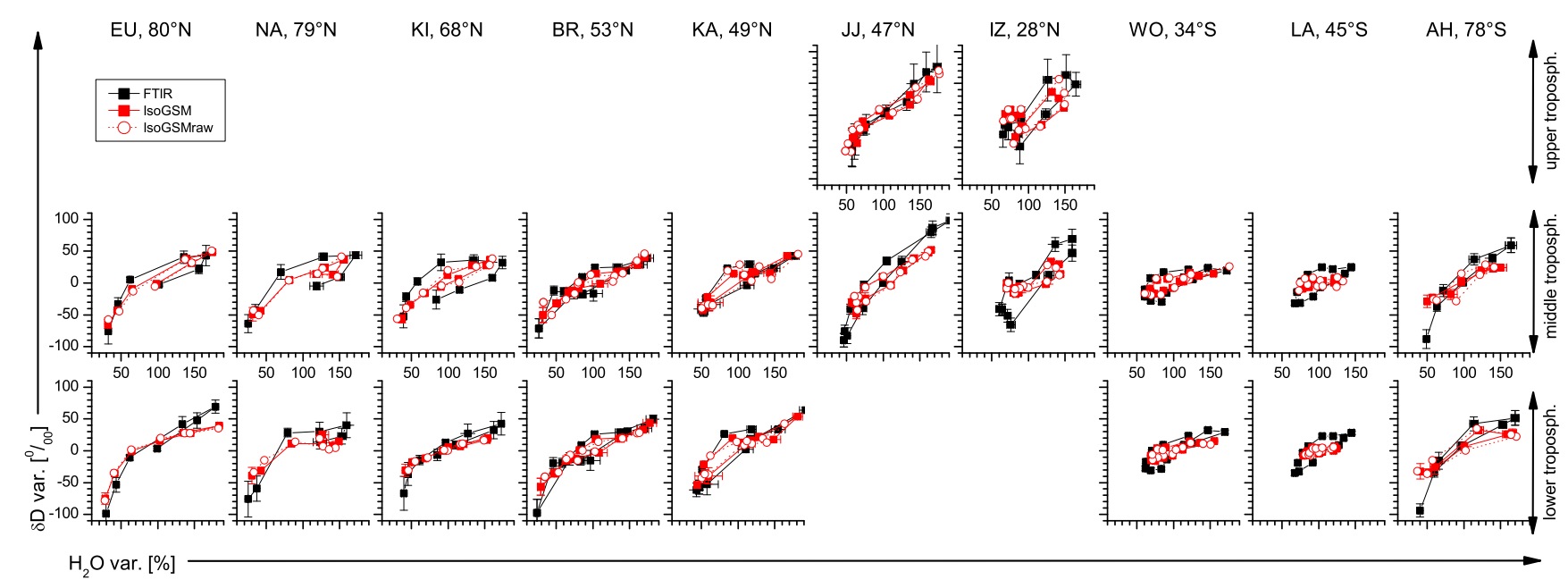

Fig. 16. Same as right graph of panel (b) of Fig. 15, but for lower, middle, and upper troposphere of all ten sites contributing to MUSICA.

basis we can document the sensitivity, vertical resolution, and error applying the well known procedures as suggested, for instance, in the textbook of C. D. Rodgers (Rodgers, 2000). This characterisation is very necessary in order to understand the complex nature of the isotopologue remote sensing data, thereby assuring its correct application (e.g. for model or satellite sensor validation).

We apply the new method for extensively characterising the water vapour isotopologue dataset produced by the ground-based remote sensing component of the project MUSICA. The dataset offers two types of profiles: first, tropospheric water vapour profiles, and second, tropospheric profiles of the isotopic composition of water vapour.

The $\mathrm{H}_{2} \mathrm{O}$ profiles have a DOFS of about 2.5-3, whereby water vapour variations from the lower up to the upper troposphere can be detected. We estimate their precision to be better than $10 \%$ throughout the troposphere at all stations. The precision of the retrieved total precipitable water vapour is estimated to be better than $1 \%$.

The profiles of the isotopic composition offer a DOFS of 1.0-1.5 for humid low-altitude sites and 1.5-2.0 for dry or high-altitude sites. The sensitivity of this product is limited to the lower and middle troposphere for the low-altitude sites (middle and upper troposphere for the high-altitude sites). Our study reveals that one has to be very careful in order to properly interpret isotopologue remote sensing data. A first problem is that the $\mathrm{H}_{2} \mathrm{O}$ and $\delta \mathrm{D}$ products are generally not representative of the same atmospheric airmass, and a second problem is that the $\delta \mathrm{D}$ product suffers from cross-dependence on atmospheric humidity. Both shortcomings significantly affect the scientific usefulness of the data. If the averaging kernels are provided for each individual observation, the aforementioned shortcomings can be well overcome by an a posteriori data treatment leading to $\mathrm{H}_{2} \mathrm{O}$ and $\delta \mathrm{D}$ profiles that are sensitive to the same atmospheric airmass and with a precision of better than $2 \%$ and $30 \%$, respectively. All the MUSICA isotopologue products obtained from ground- and space-based remote sensing techniques (NDACC-FTIR and METOP/IASI products, respectively) undergo this a posteriori treatment, which consists of a simple a posteriori matrix multiplication according to Eq. (20).

The ground-based MUSICA experiments offer a longterm record of tropospheric water vapour profiles and of its isotopic composition for ten globally distributed sites, whereby the good network-wide consistency is demonstrated empirically by our mid-infrared $\mathrm{CO}_{2}$ retrievals. Due to its long-term characteristic, its network-wide consistency, and the extensively documented error levels, the dataset is promising for investigating the reliability of climate models. This potential is briefly indicated by our modelmeasurement comparison of Sect. 6. Taking the MUSICA measurements as reference, we identify some deficits in the modeled atmospheric water cycle. First, the model seems to underestimate $\delta \mathrm{D}$ values close to the humidity source region (low altitude/latitude sites) and overestimates $\delta \mathrm{D}$ far away from the humidity source regions (high altitude/latitude sites). Second, we observe that the tropospheric water mass tends to be more depleted in HDO in autumn if compared to spring, although the humidity levels are the same. This variability in the isotopic composition is only partly captured by the model.

In the framework of this technical paper, we do not attempt to scientifically interpret model-measurement differences. Instead, we hope that we can encourage the modeling community to collaborate with us for a scientific exploitation of the dataset. The whole dataset - including the detailed error estimations for each individual observation - will soon be made freely available for the interested scientific community via an FTP server. 
Acknowledgements. We would like to thank the many different technicians, PhD students, post-docs, and scientists from the different research groups that have been involved in the NDACC-FTIR activities during the last two decades. Thanks to their excellent work (maintenance, calibration, observation activities, etc.), high quality long-term datasets can be generated.

The Eureka measurements were made at the Polar Environment Atmospheric Research Laboratory (PEARL) by the Canadian Network for the Detection of Atmospheric Change (CANDAC), led by James R. Drummond, and in part by the Canadian Arctic ACE Validation Campaigns, led by Kaley A. Walker. They were supported by the AIF/NSRIT, CFI, CFCAS, CSA, EC, GOC-IPY, NSERC, NSTP, OIT, PCSP, and ORF. The authors wish to thank Rebecca Batchelor, Rodica Lindenmaier, PEARL site manager Pierre F. Fogal, the CANDAC operators, and the staff at Environment Canada's Eureka weather station for their contributions to data acquisition, and logistical and on-site support.

We thank the Alfred Wegener Institut Bremerhaven for support in using the AWIPEV research base, Spitsbergen, Norway. The work has been supported by EU-Project NORS.

We would like to thank Uwe Raffalski and Peter Völger for technical support at IRF Kiruna.

The University of Liége contribution to the present work has primarily been supported by the A3C PRODEX program, funded by the Belgian Federal Science Policy Office (BELSPO, Brussels), and by the Swiss GAW-CH program of MeteoSwiss (Zürich). Laboratory developments and mission expenses were funded by FRS-FNRS and the Fédération Wallonie-Bruxelles, respectively. We thank the International Foundation High Altitude Research Stations Jungfraujoch and Gornergrat (HFSJG, Bern) for supporting the facilities needed to perform the observations. We further acknowledge the vital contribution from all the colleagues who have performed the observations used here.

E. Sepúlveda enjoys a pre-doctoral fellowship from the Spanish Ministry of Education.

Measurements at Wollongong are supported by the Australian Research Council, grant DP110103118.

We would like to thank Antarctica New Zealand and the Scott Base staff for providing logistical support for the NDACC-FTIR measurement program at Arrival Heights.

This study has been conducted in the framework of the project MUSICA, which is funded by the European Research Council under the European Community's Seventh Framework Programme (FP7/2007-2013)/ERC Grant agreement number 256961.

We acknowledge the support by the Deutsche Forschungsgemeinschaft and the Open Access Publishing Fund of the Karlsruhe Institute of Technology.

The service charges for this open access publication

have been covered by a Research Centre of the

Helmholtz Association.

Edited by: H. Worden

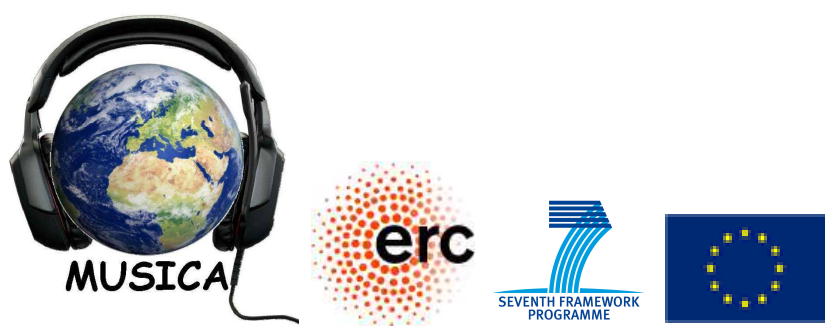

\section{References}

Aemisegger, F., Sturm, P., Graf, P., Sodemann, H., Pfahl, S., Knohl, A., and Wernli, H.: Measuring variations of $\delta^{18} \mathrm{O}$ and $\delta^{2} \mathrm{H}$ in atmospheric water vapour using two commercial laser-based spectrometers: an instrument characterisation study, Atmos. Meas. Tech., 5, 1491-1511, doi:10.5194/amt-5-1491-2012, 2012.

Batchelor, R. L., Strong, K., Lindenmaier, R., Mittermeier, R. L., Fast, H., Drummond, J. R., and Fogal, P. F.: A new Bruker IFS 125HR FTIR spectrometer for the Polar Environment Atmospheric Research Laboratory at Eureka, Canada: measurements and comparison with the existing Bomem DA8 spectrometer, J. Atmos. Ocean. Technol., 26, 1328-1340, 2009.

Blumenstock, T., Kopp, G., Hase, F., Hochschild, G., Mikuteit, S., Raffalski, U., and Ruhnke, R.: Observation of unusual chlorine activation by ground-based infrared and microwave spectroscopy in the late Arctic winter 2000/01, Atmos. Chem. Phys., 6, 897905, doi:10.5194/acp-6-897-2006, 2006.

Boesch, H., Deutscher, N. M., Warneke, T., Byckling, K., Cogan, A. J., Griffith, D. W. T., Notholt, J., Parker, R. J., and Wang, Z.: $\mathrm{HDO} / \mathrm{H}_{2} \mathrm{O}$ ratio retrievals from GOSAT, Atmos. Meas. Tech. Discuss., 5, 6643-6677, doi:10.5194/amtd-5-6643-2012, 2012.

Craig, H.: Standard for Reporting concentrations of Deuterium and Oxygen-18 in natural waters, Science, 13, 1833-1834, doi:10.1126/science.133.3467.1833, 1961.

Dyroff, C., Fütterer, D., and Zahn, A.: Compact diode-laser spectrometer ISOWAT for highly sensitive airborne measurements of water-isotope ratios, Appl. Phys. B, 98, 537-548, doi:10.1007/s00340-009-3775-6, 2010.

Ehhalt, D.: Vertical profiles of HTO, HDO, and $\mathrm{H}_{2} \mathrm{O}$ in the Troposphere, Rep. NCAR-TN/STR-100, Natl. Cent. for Atmos. Res., Boulder, Colo., 1974.

Frankenberg, C., Yoshimura, K., Warneke, T., Aben, I., Butz, A., Deutscher, N., Griffith, D., Hase, F., Notholt, J., Schneider, M., Schrejver, H., and Röckmann, T.: Dynamic processes governing lower-tropospheric $\mathrm{HDO} / \mathrm{H}_{2} \mathrm{O}$ ratios as observed from space and ground, Science, 325, 1374-1377, doi:10.1126/science.1173791, 2009.

Frankenberg, C., Wunch, D., Toon, G., Risi, C., Scheepmaker, R., Lee, J.-E., Wennberg, P., and Worden, J.: Water vapor isotopologues retrievals from high resolution GOSAT short-wave infrared spectra, Atmos. Meas. Tech. Discuss., 5, 6357-6386, doi:10.5194/amtd-5-6357-2012, 2012.

García, O. E., Schneider, M., Redondas, A., González, Y., Hase, F., Blumenstock, T., and Sepúlveda, E.: Investigating the longterm evolution of subtropical ozone profiles applying groundbased FTIR spectrometry, Atmos. Meas. Tech., 5, 2917-2931, doi:10.5194/amt-5-2917-2012, 2012. 
Gisi, M., Hase, F., Dohe, S., and Blumenstock, T.: Camtracker: a new camera controlled high precision solar tracker system for FTIR-spectrometers, Atmos. Meas. Tech., 4, 47-54, doi:10.5194/amt-4-47-2011, 2011.

Hase, F., Blumenstock, T., and Paton-Walsh, C.: Analysis of the instrumental line shape of high-resolution Fourier transform IR spectrometers with gas cell measurements and new retrieval software, Appl. Optics, 38, 3417-3422, 1999.

Hase, F., Hannigan, J. W., Coffey, M. T., Goldman, A., Höpfner, M., Jones, N. B., Rinsland, C. P., and Wood, S.: Intercomparison of retrieval codes used for the analysis of high-resolution, J. Quant. Spectrosc. Ra., 87, 25-52, 2004.

Herbin, H., Hurtmans, D., Clerbaux, C., Clarisse, L., and Coheur, P.-F.: $\mathrm{H}_{2}{ }^{16} \mathrm{O}$ and HDO measurements with IASI/MetOp, Atmos. Chem. Phys., 9, 9433-9447, doi:10.5194/acp-9-9433-2009, 2009.

Kanamitsu, M., Kumar, A., Juang, H.-M., Schemm, J.-K., Wang, W., Yang, F., Hong, S.-Y., Peng, P., Chen, W., Moorthi, S., and Ji, M.: NCEP dynamical seasonal forcast system 2000, B. Am. Meteorol. Soc., 83, 1019-1037, 2002.

Kohlhepp, R.: Trend von $\mathrm{CO}_{2}$ aus bodengebundenen FTIRMessungen in Kiruna, Seminararbeit am Institut für Meteorologie und Klimaforschung (IMK-ASF), Forschungszentrum und Universität Karlsruhe, 2007.

Kohlhepp, R., Ruhnke, R., Chipperfield, M. P., De Mazière, M., Notholt, J., Barthlott, S., Batchelor, R. L., Blatherwick, R. D., Blumenstock, Th., Coffey, M. T., Demoulin, P., Fast, H., Feng, W., Goldman, A., Griffith, D. W. T., Hamann, K., Hannigan, J. W., Hase, F., Jones, N. B., Kagawa, A., Kaiser, I., Kasai, Y., Kirner, O., Kouker, W., Lindenmaier, R., Mahieu, E., Mittermeier, R. L., Monge-Sanz, B., Morino, I., Murata, I., Nakajima, H., Palm, M., Paton-Walsh, C., Raffalski, U., Reddmann, Th., Rettinger, M., Rinsland, C. P., Rozanov, E., Schneider, M., Senten, C., Servais, C., Sinnhuber, B.-M., Smale, D., Strong, K., Sussmann, R., Taylor, J. R., Vanhaelewyn, G., Warneke, T., Whaley, C., Wiehle, M., and Wood, S. W.: Observed and simulated time evolution of $\mathrm{HCl}, \mathrm{ClONO}_{2}$, and $\mathrm{HF}$ total column abundances, Atmos. Chem. Phys., 12, 3527-3556, doi:10.5194/acp12-3527-2012, 2012.

Kuang, Z., Toon, G., Wennberg, P., and Yung, Y.: Measured $\mathrm{HDO} / \mathrm{H}_{2} \mathrm{O}$ ratios across the tropical tropopause, Geophys. Res. Lett., 30, 251-254, 2003.

Lacour, J.-L., Risi, C., Clarisse, L., Bony, S., Hurtmans, D., Clerbaux, C., and Coheur, P.-F.: Mid-tropospheric $\delta \mathrm{D}$ observations from IASI/MetOp at high spatial and temporal resolution, Atmos. Chem. Phys., 12, 10817-10832, doi:10.5194/acp12-10817-2012, 2012.

Lossow, S., Steinwagner, J., Urban, J., Dupuy, E., Boone, C. D., Kellmann, S., Linden, A., Kiefer, M., Grabowski, U., Glatthor, N., Höpfner, M., Röckmann, T., Murtagh, D. P., Walker, K. A., Bernath, P. F., von Clarmann, T., and Stiller, G. P.: Comparison of HDO measurements from Envisat/MIPAS with observations by Odin/SMR and SCISAT/ACE-FTS, Atmos. Meas. Tech., 4, 1855-1874, doi:10.5194/amt-4-1855-2011, 2011.

Nassar, R., Bernath, P. F., Boone, C. D., Gettelman, A., McLeod, S. D., and Rinsland, C. P.: Variability in $\mathrm{HDO} / \mathrm{H}_{2} \mathrm{O}$ abundance ratios in the tropical tropopause layer, J. Geophys. Res., 112, D21305, doi:10.1029/2007JD008417, 2007.
Notholt, J., Meier, A., and Peil, S.: Total Column Densities of Tropospheric and Stratospheric Trace Gases in the Undisturbed Arctic Summer Atmosphere, J. Atmos. Chem., 20, 311-332, doi:10.1175/2009JTECHA1215.1, 1995.

Payne, V. H., Noone, D., Dudhia, A., Piccolo, C., and Grainger, R. G.: Global satellite measurements of HDO and implications for understanding the transport of water vapour into the stratosphere, Q. J. Roy. Meteorol. Soc., 133, 1459-1471, doi:10.1002/qj.127, 2007.

Pierrehumbert, R.: Thermostats, Radiator Fins, and the Local Runaway Greenhouse, J. Atmos. Sci., 52, 1784-1806, 1995.

Reuter, M., Buchwitz, M., Schneising, O., Hase, F., Heymann, J., Guerlet, S., Cogan, A. J., Bovensmann, H., and Burrows, J. P.: A simple empirical model estimating atmospheric $\mathrm{CO}_{2}$ background concentrations, Atmos. Meas. Tech., 5, 1349-1357, doi:10.5194/amt-5-1349-2012, 2012.

Risi, C., Noone, D., Worden, J., Frankenberg, C., Stiller, G., Kiefer, M., Funke, B., Walker, K., Bernath, P., Schneider, M., Bony, S., Lee, J., Brown, D., and Sturm, C.: Process-evaluation of tropospheric humidity simulated by general circulation models using water vapor isotopic observations. Part 2: an isotopic diagnostic to understand the mid and upper tropospheric moist bias in the tropics and subtropics, J. Geophys. Res., 117, D05304, doi:10.1029/2011JD016623, 2012a.

Risi, C., Noone, D., Worden, J., Frankenberg, C., Stiller, G., Kiefer, M., Funke, B., Walker, K., Bernath, P., Schneider, M., Wunch, D., Sherlock, V., Deutscher, N., Griffith, D., Wennberg, P., Strong, K., Barthlott, S., Hase, F., G. O., Smale, D., Mahieu, E., Sayres, D., Bony, S., Lee, J., Brown, D., Uemura, R., and Sturm, C.: Process-evaluation of tropospheric humidity simulated by general circulation models using water vapor isotopic observations. Part 1: comparison between models and datasets, J. Geophys. Res., 117, D05303, doi:10.1029/2011JD016621, 2012b.

Rodgers, C.: Inverse Methods for Atmospheric Sounding: Theory and Praxis, World Scientific Publishing Co., Singapore, 2000.

Rothman, L. S., Gordon, I. E., Barbe, A., Chris Benner, D., Bernath, P. F., Birk, M., Boudon, V., Brown, L. R., Campargue, A., Champion, J.-P., Chance, K., Coudert, L. H., Dana, V., Devi, V. M., Fally, S., Flaud, J.-M., Gamache, R. R., Goldman, A., Jacquemart, D., Kleiner, I., Lacome, N., Lafferty, W. J., Mandin, J.-Y., Massie, S. T., Mikhailenko, S. N., Miller, C. E., Moazzen-Ahmadi, N., Naumenko, O. V., Nikitin, A. V., Orphal, J., Perevalov, V. I., Perrin, A., Predoi-Cross, A., Rinsland, C. P., Rotger, M., Simecková, M., Smith, M. A. H., Sung, K., Tashkun, S. A., Tennyson, J., Toth, R. A., Vandaele, A. C., and Vander-Auwera, J.: The HITRAN 2008 molecular spectroscopic database, J. Quant. Spectrosc. Ra., 110, 533-572, doi:10.1016/j.jqsrt.2009.02.013, 2009.

Schmidt, G. A., Hoffmann, G., Shindell, D. T., and Hu, Y.: Modeling atmospheric stable water isotopes and the potential for constraining cloud processes and stratospheretroposphere water exchange, J. Geophys. Res., 110, D21314, doi:10.1029/2005JD005790, 2005.

Schneider, M. and Hase, F.: Technical Note: Recipe for monitoring of total ozone with a precision of around 1 DU applying midinfrared solar absorption spectra, Atmos. Chem. Phys., 8, 63-71, doi:10.5194/acp-8-63-2008, 2008.

Schneider, M. and Hase, F.: Ground-based FTIR water vapour profile analyses, Atmos. Meas. Tech., 2, 609-619, doi:10.5194/amt- 
2-609-2009, 2009.

Schneider, M. and Hase, F.: Optimal estimation of tropospheric $\mathrm{H}_{2} \mathrm{O}$ and $\delta \mathrm{D}$ with IASI/METOP, Atmos. Chem. Phys., 11, 11207-11220, doi:10.5194/acp-11-11207-2011, 2011.

Schneider, M., Blumenstock, T., Chipperfield, M. P., Hase, F., Kouker, W., Reddmann, T., Ruhnke, R., Cuevas, E., and Fischer, H.: Subtropical trace gas profiles determined by ground-based FTIR spectroscopy at Izaña $\left(28^{\circ} \mathrm{N}, 16^{\circ} \mathrm{W}\right)$ : Five-year record, error analysis, and comparison with 3-D CTMs, Atmos. Chem. Phys., 5, 153-167, doi:10.5194/acp-5-153-2005, 2005.

Schneider, M., Hase, F., and Blumenstock, T.: Water vapour profiles by ground-based FTIR spectroscopy: study for an optimised retrieval and its validation, Atmos. Chem. Phys., 6, 811-830, doi:10.5194/acp-6-811-2006, 2006a.

Schneider, M., Hase, F., and Blumenstock, T.: Ground-based remote sensing of $\mathrm{HDO} / \mathrm{H}_{2} \mathrm{O}$ ratio profiles: introduction and validation of an innovative retrieval approach, Atmos. Chem. Phys., 6, 4705-4722, doi:10.5194/acp-6-4705-2006, 2006b.

Schneider, M., Hase, F., Blumenstock, T., Redondas, A., and Cuevas, E.: Quality assessment of $\mathrm{O}_{3}$ profiles measured by a state-of-the-art ground-based FTIR observing system, Atmos. Chem. Phys., 8, 5579-5588, doi:10.5194/acp-8-5579-2008, 2008.

Schneider, M., Romero, P. M., Hase, F., Blumenstock, T., Cuevas, E., and Ramos, R.: Continuous quality assessment of atmospheric water vapour measurement techniques: FTIR, Cimel, MFRSR, GPS, and Vaisala RS92, Atmos. Meas. Tech., 3, 323338, doi:10.5194/amt-3-323-2010, 2010a.

Schneider, M., Yoshimura, K., Hase, F., and Blumenstock, T.: The ground-based FTIR network's potential for investigating the atmospheric water cycle, Atmos. Chem. Phys., 10, 3427-3442, doi:10.5194/acp-10-3427-2010, 2010b.

Schneider, M., Hase, F., Blavier, J.-F., Toon, G. C., and Leblanc, T.: An empirical study on the importance of a speed-dependent Voigt line shape model for tropospheric water vapor profile remote sensing, J. Quant. Spectrosc. Ra., 112, 465-474, doi:10.1016/j.jqsrt.2010.09.008, 2011.

Sepúlveda, E., Schneider, M., Hase, F., García, O. E., GomezPelaez, A., Dohe, S., Blumenstock, T., and Guerra, J. C.: Longterm validation of tropospheric column-averaged $\mathrm{CH}_{4}$ mole fractions obtained by mid-infrared ground-based FTIR spectrometry, Atmos. Meas. Tech., 5, 1425-1441, doi:10.5194/amt-5-14252012, 2012.

Spencer, R. and Braswell, W.: How Dry is the Tropical Free Troposphere? Implications for Global Warming Theory, B. Am. Meteorol. Soc., 78, 1097-1106, 1997.

Steinwagner, J., Milz, M., von Clarmann, T., Glatthor, N., Grabowski, U., Höpfner, M., Stiller, G. P., and Röckmann, T.: HDO measurements with MIPAS, Atmos. Chem. Phys., 7, 26012615, doi:10.5194/acp-7-2601-2007, 2007.

Sussmann, R. and Borsdorff, T.: Technical Note: Interference errors in infrared remote sounding of the atmosphere, Atmos. Chem. Phys., 7, 3537-3557, doi:10.5194/acp-7-3537-2007, 2007.
Sussmann, R., Borsdorff, T., Rettinger, M., Camy-Peyret, C., Demoulin, P., Duchatelet, P., Mahieu, E., and Servais, C.: Technical Note: Harmonized retrieval of column-integrated atmospheric water vapor from the FTIR network - first examples for longterm records and station trends, Atmos. Chem. Phys., 9, 89878999, doi:10.5194/acp-9-8987-2009, 2009.

Tremoy, G., Vimeux, F., Cattani, O., Mayaki, S., de Souley, I., and Favreau, G.: Measurements of water vapor isotope ratios with wavelength scanned cavity ring-down spectroscopy technology: new insights and important caveats for deuterium excess measurements in tropical areas in comparison with isotope-ratio mass spectrometry, Rapid Commun. Mass Spectrom., 25, 3469-3480, doi:10.1002/rcm.5252, 2011.

Trenberth, K., Fasullo, J., and Kiehl, J.: Earth's global energy budget, B. Am. Meteorol. Soc., 90, 311-324, doi:10.1175/2008BAMS2634.1, 2009.

Velazco, V., Wood, S. W., Sinnhuber, M., Kramer, I., Jones, N. B., Kasai, Y., Notholt, J., Warneke, T., Blumenstock, T., Hase, F., Murcray, F. J., and Schrems, O.: Annual variation of strato-mesospheric carbon monoxide measured by ground-based Fourier transform infrared spectrometry, Atmos. Chem. Phys., 7, 1305-1312, doi:10.5194/acp-7-1305-2007, 2007.

Webster, C. R. and Heymsfield, A. J.: Water Isotope Ratios H/D, ${ }^{18} \mathrm{O} /{ }^{16} \mathrm{O},{ }^{17} \mathrm{O} /{ }^{16} \mathrm{O}$ in and out of Clouds Map Dehydration Pathways, Science, 302, 1742-1745, doi:10.1126/science.1089496, 2003.

Worden, J., Bowman, K., Noone, D., Beer, R., Clough, S., Eldering, A., Fisher, B., Goldman, A., Gunson, M., Herman, R., Kulawik, S., Lampel, M., Luo, M., Osterman, G., Rinsland, C., Rodgers, C., Sander, S., Shephard, M., and Worden, H.: TES observations of the tropospheric $\mathrm{HDO} / \mathrm{H}_{2} \mathrm{O}$ ratio: retrieval approach and characterization, J. Geophys. Res., 11, D16309, doi:10.1029/2005JD006606, 2006.

Worden, J., Noone, D., Bowman, K., Beer, R., Eldering, A., Fisher, B., Gunson, M., Goldman, A., Herman, R., Kulawik, S. S., Lampel, M., Osterman, G., Rinsland, C., Rodgers, C., Sander, S., Shephard, M., Webster, R., and Worden, H.: Importance of rain evaporation and continental convection in the tropical water cycle, Nature, 445, 528-532, doi:10.1038/nature05508, 2007.

Yoshimura, K. and Kanamitsu, M.: V Dynamical global downscalling of global reanalysis, Mon. Weather Rev., 136, 2983-2998, 2008.

Yoshimura, K., Kanamitsu, M., Noone, D., and Oki, T.: Historical isotope simulation using Reanalysis atmospheric data, J. Geophys. Res., 113, D19108, doi:10.1029/2008JD010074, 2008.

Zahn, A.: Constraints on 2-Way Transport across the Arctic Tropopause Based on $\mathrm{O}_{3}$, Stratospheric Tracer $\left(\mathrm{SF}_{6}\right)$ Ages, and Water Vapor Isotope (D, T) Tracers, J. Atmos. Chem., 39, 303325, 2001.

Zander, R., Mahieu, E., Demoulin, P., Duchatelet, P., Roland, G., Servais, C., De Maziere, M., Reimann, S., and Rinsland, C. P.: Our changing atmosphere: Evidence based on long-term infrared solar observations at the Jungfraujoch since 1950, Sci. Total Environ., 391, 184-195, 2008. 